International Journal of Physical Modelling in Geotechnics

Volume 17 Issue 3

Lateral boundary effects in centrifuge foundation tests

Ullah, Hu, Stanier and White
International Journal of Physical Modelling in Geotechnics,

2017, 17(3), 144-160

http://dx.doi.org/10.1680/jphmg. 15.00034

Paper 1500034

Received 20/09/2015 Accepted 05/03/2016

Published online 13/04/2016

Keywords: computational mechanics/foundations/

offshore engineering

ICE Publishing: All rights reserved

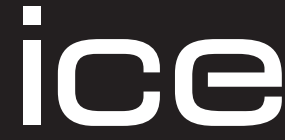

Institution of Civil Engineers

\title{
Lateral boundary effects in centrifuge foundation tests
}

1 Shah Neyamat Ullah BSC

PhD candidate, Centre for Offshore Foundation Systems, University of Western Australia, Crawley, WA, Australia

(corresponding author: 20008177@student.uwa.edu.au)

2 Yuxia Hu PhD

Professor, School of Civil and Resource Engineering, University of Western Australia, Crawley, WA, Australia
3 Samuel Stanier PhD

Research Fellow, Centre for Offshore Foundation Systems, University of Western Australia, Crawley, WA, Australia

4 David White PhD

Winthrop Professor, Centre for Offshore Foundation Systems,

University of Western Australia, Crawley, WA, Australia
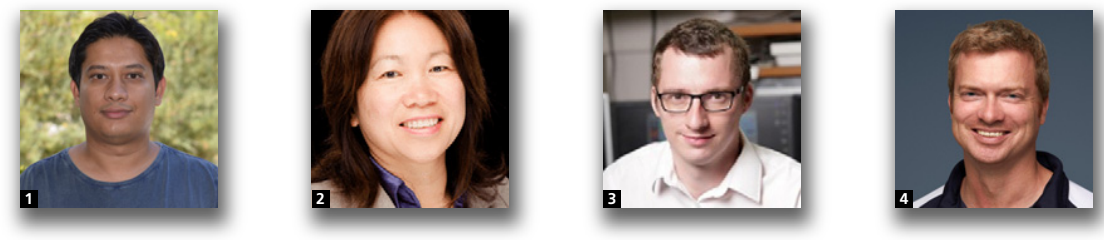

Large deformation finite-element analyses were conducted to explore the effect of the container lateral boundary in centrifuge tests where a large offshore foundation is tested. A spudcan foundation, typically used to support jack-up drilling rigs, was penetrated into uniform clay, uniform sand and sand overlying clay stratigraphies under rough and smooth lateral boundary conditions. The effect that the proximity of the container lateral boundary has on the measured load-penetration response is quantified. The boundary impact varies with the soil profile and boundary roughness, and for sand-only or sand-over-clay conditions the required separation between the foundation and the container boundary is far greater than in clay-only conditions. In most cases, during large penetration of the spudcan foundation, the largest influence from the lateral boundary was on peak resistance, and diminished during the subsequent deeper penetration. For practical use, a centrifuge container design chart is proposed to check whether the dimensions are adequate for the foundation and model size to be used in an experiment. It is shown that the results from many earlier studies could have been potentially influenced by container boundary effects.

\section{Notation}

A foundation area

$B \quad$ cone diameter

c cohesion in clay

D foundation diameter

$d \quad$ penetration depth

E modulus of elasticity

$H_{\mathrm{s}} \quad$ sand thickness or height

$I_{\mathrm{D}} \quad$ sand relative density

$K_{0} \quad$ earth pressure coefficient at rest

$L_{\mathrm{BD}} \quad$ lateral boundary distance

$N \quad$ remeshing step

$N_{\text {c }} \quad$ shallow clay bearing capacity factor

$N_{\text {cd }} \quad$ deep clay bearing capacity factor

$q_{\text {nom }} \quad$ nominal bearing pressure

$s_{\mathrm{u}} \quad$ undrained shear strength of clay

$\gamma_{c}^{\prime} \quad$ effective unit weight of clay

$\gamma_{\mathrm{s}}^{\prime} \quad$ effective unit weight of sand $\delta \quad$ foundation displacement increment

$\tau \quad$ shear stress

$v \quad$ Poisson's ratio

$\phi \quad$ friction angle

$\psi \quad$ dilation angle

\section{Introduction}

The jack-up drilling rigs used for oil and gas exploration in shallow water are supported on spudcan foundations. The spudcan, commonly, has a quasi-circular or polygonal shape with a conical underside. During jack-up rig installation, prior to drilling, these spudcan foundations are penetrated into the seabed under ballast pre-loading from the hull until the desired resistance is reached, a state defined by the expected operational and storm loading of the rig. Due to their size, field testing of spudcan foundations is uneconomical. Instead their behaviour has largely been studied in the laboratory using centrifuge 
International Journal of Physical Modelling in Geotechnics Volume 17 Issue 3
Lateral boundary effects in centrifuge

foundation tests

Ullah, Hu, Stanier and White models so as to maintain the stress similitude between the model and the prototype (e.g. Craig and Chua, 1990; Hossain and Randolph, 2009; Lee, 2009, Lee et al., 2013; Teh, 2007).

Such tests are conducted in containers (also referred to as strongboxes) with rigid boundaries. The strongbox dimensions should be large enough to simulate an infinite soil domain with negligible boundary effects. It is also commonly acknowledged that the foundation model needs to be placed at a certain distance $\left(L_{\mathrm{BD}}\right)$ away from the lateral boundary of the strongbox to simulate the infinite space in the field (Figure 1).

As the success of centrifuge tests depends on the accuracy of the measured load-penetration response during foundation penetration, the $L_{\mathrm{BD}}$ should be sufficient such that the loadpenetration response is practically unaffected by the presence of the boundary. The potential influence of the strongbox boundary needs to be assessed based on its distance $\left(L_{\mathrm{BD}}\right)$ and roughness. Therefore, with fixed strongbox dimensions (length $\times$ width), the foundation models need to be carefully sized and located.

Previous researches on container boundary effects were mainly concerned with cone penetration tests (CPTs) in sand. Table 1 lists the recommendations of lateral boundary distances suggested by different researchers, primarily for tests in dense sand. However, tests on loose sand $\left(I_{\mathrm{D}} \sim 30 \%\right.$, where $I_{\mathrm{D}}$ is the

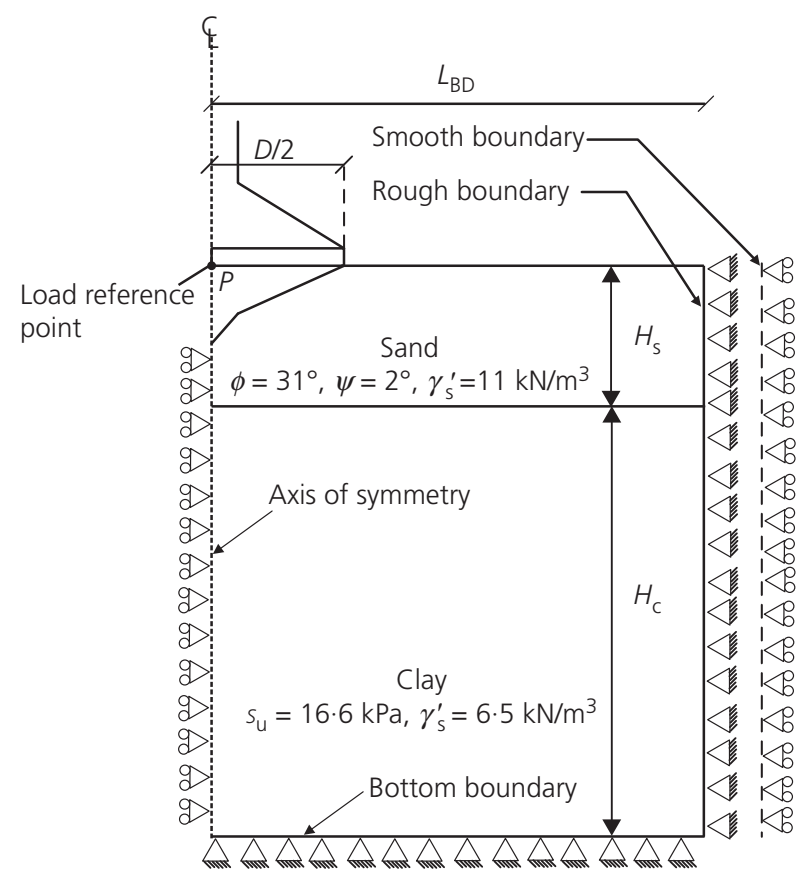

Figure 1. Problem geometry sand relative density) can also be affected by the boundary proximity but to a lesser extent (Schnaid and Houlsby, 1991). As Table 1 shows that these recommendations are highly scattered and no common agreement exists among researchers (Ghafghazi, 2011). Moreover, these CPT studies are not directly applicable to large offshore foundations as marked differences in soil flow mechanisms are expected. The CPT exhibits cavity expansion in soils and the spudcan penetration test displays localised surface heave or flow-around mechanisms. There are no existing guidelines or recommendations for suitable strongbox dimensions in centrifuge tests involving large foundations.

This paper uses large deformation finite-element (LDFE) analyses (incorporating the remeshing and interpolation with small strain (RITSS) technique originally developed by $\mathrm{Hu}$ and Randolph, 1998a) to develop a design chart to assist centrifuge test planning in a strongbox. The soil profiles simulated span single (uniform clay (UC) or uniform sand (US)) and layered (sand overlying clay (SC)) seabed conditions.

\section{Analysis methodology}

\subsection{The LDFE/RITSS technique}

LDFE analysis incorporating the RITSS formulation originally developed by $\mathrm{Hu}$ and Randolph (1998a) has been adopted in this study. The method falls in the finite element (FE) category of arbitrary Lagrangian Eulerian, which circumvents the inaccuracy caused by excessive mesh distortion that is associated with small-strain FE methods (Wang and Carter, 2002; Zhou, 2008). In the RITSS approach, a series of smallstrain analyses is performed with frequent automatic mesh regeneration, followed by interpolation of the stress state and material properties from the old mesh to the new mesh. The process of remeshing and interpolation is repeated until the desired penetration depth is achieved. This LDFE/RITSS method has been successfully applied to many challenging geotechnical problems including spudcan penetration (Hossain et al., 2004, 2005; Yu et al., 2012), strip and circular footing performance (Wang and Carter, 2002) and installation of suction caisson (Zhou, 2008).

\subsection{Summary of numerical analyses}

Figure 1 displays the overview of the problem studied under an axisymmetric condition. Two different lateral boundary conditions have been investigated.

- A perfectly rough boundary $(R B)$ : Where the lateral boundary was restrained in both radial and vertical directions (shown as hinge in Figure 1).

- A perfectly smooth boundary ( $S B$ ): Where only the radial movement was restrained and the vertical movement was set free (shown as roller in Figure 1). 


\begin{tabular}{llll} 
Researchers & $I_{\mathrm{D}}$ & $L_{\mathrm{BD}}$ & Boundary condition \\
\hline Last (1979) $^{\mathrm{a}}$ & - & $14 B^{\mathrm{b}}$ & Rigid walled chamber \\
Parkin and Lunne (1982) & $90 \%$ & $25 B$ & Flexible walled chamber \\
Phillips and Valsangkar (1987) & $87 \%$ & $5 B$ & Rigid walled container \\
Bolton et al. (1999) & 58 and $91 \%$ & $\sim 10 B$ & Rigid container \\
Ahmadi and Robertson (2008) & $90 \%$ & $40 B$ & Numerical study with four different \\
& & & boundary conditions
\end{tabular}

asee Phillips and Valsangkar (1987)

${ }^{\mathrm{b}} B$ is the cone diameter

Table 1. Recommendation of test boundary distance for CPT in

sand

Hence, a perfectly SB excludes any generation of shear stresses $(\tau)$ along the boundary, whereas shear stresses can generate along the perfectly RB to a magnitude equivalent to the shear strength of soil. To simplify the analyses, no intermediate boundary roughness conditions have been considered in this study, since the perfectly rough and smooth boundaries serve as bounds. The lateral boundary distance $\left(L_{\mathrm{BD}}\right)$ is defined as the distance measured from the centre of the foundation to the inner edge of the strongbox (Figure 1).
Table 2 and Figure 2 summarise the soil profiles $\left(H_{\mathrm{s}} / D\right.$ or $D / H_{\mathrm{s}}$, where $D$ is the spudcan diameter) and the strongbox sizes $\left(L_{\mathrm{BD}} / D\right)$ that were modelled. Three different soil stratigraphies have been considered: $(a) \mathrm{UC}$ ( i.e. $H_{\mathrm{s}} / D=0$ ), (b) US (i.e. $\left.D / H_{\mathrm{s}}=0\right)$ and $(c) \mathrm{SC}$ (i.e. $0<\left(H_{\mathrm{s}} / D\right.$ or $\left.\left.D / H_{\mathrm{s}}\right) \leq 1\right)$. For US and $\mathrm{SC}$ soils, $L_{\mathrm{BD}}$ varied as $1 \cdot 5 D$ to $10 D$. For UC soil, there were two additional cases with $L_{\mathrm{BD}}$ of $0 \cdot 8 \mathrm{D}$ and $1 D$ considered. The $L_{\mathrm{BD}}=10 D$ was suitable as a reference case without the effect of the lateral boundary on penetration

\begin{tabular}{lcllccl}
\hline Case identity $^{\mathrm{a}}$ & $D: \mathrm{m}$ & $H_{\mathrm{s}} / D$ & $\mathrm{Su}_{\mathrm{u}}: \mathrm{kPa}$ & $\phi:$ deg & $\psi$ : deg & $L_{\mathrm{BD}}$ \\
\hline UC-RB & 10 & 0 & $16 \cdot 6$ & 0 & 0 & $0 \cdot 8 D, 1 D, 1 \cdot 5 D, 2 D, 3 D, 5 D, 10 D$ \\
UC-SB & 10 & 0 & $16 \cdot 6$ & 0 & 0 & $0 \cdot 8 D, 1 D, 1 \cdot 5 D, 2 D, 3 D, 5 D, 10 D$ \\
US-RB & 10 & $\infty$ & - & 31 & 2 & $1 \cdot 5 D, 2 D, 2 \cdot 5 D, 3 D, 5 D, 10 D$ \\
US-SB & 10 & $\infty$ & - & 31 & 2 & $1 \cdot 5 D, 2 D, 2 \cdot 5 D, 3 D, 5 D, 10 D$ \\
SC-RB-0 & 16 & $0 \cdot 375$ & $16 \cdot 6$ & 31 & 2 & $1 \cdot 5 D, 2 D, 2 \cdot 5 D, 3 D, 5 D, 10 D$ \\
SC-RB-1 & 14 & $0 \cdot 42$ & $16 \cdot 6$ & 31 & 2 & $1 \cdot 5 D, 2 D, 2 \cdot 5 D, 3 D, 5 D, 10 D$ \\
SC-RB-2 & 12 & $0 \cdot 5$ & $16 \cdot 6$ & 31 & 2 & $1 \cdot 5 D, 2 D, 2 \cdot 5 D, 3 D, 5 D, 10 D$ \\
SC-RB-3 & 10 & $0 \cdot 6$ & $16 \cdot 6$ & 31 & 2 & $1 \cdot 5 D, 2 D, 2 \cdot 5 D, 3 D, 5 D, 10 D$ \\
SC-RB-4 & 8 & $0 \cdot 75$ & $16 \cdot 6$ & 31 & 2 & $1 \cdot 5 D, 2 D, 2 \cdot 5 D, 3 D, 5 D, 10 D$ \\
SC-RB-5 & 6 & 1 & $16 \cdot 6$ & 31 & 2 & $1 \cdot 5 D, 2 D, 2 \cdot 5 D, 3 D, 5 D, 10 D$ \\
SC-RB-6 & 6 & 2 & $16 \cdot 6$ & 31 & 2 & $1 \cdot 5 D, 2 D, 2 \cdot 5 D, 3 D, 5 D, 10 D$ \\
SC-SB-0 & 16 & $0 \cdot 375$ & $16 \cdot 6$ & 31 & 2 & $1 \cdot 5 D, 2 D, 2 \cdot 5 D, 3 D, 5 D, 10 D$ \\
SC-SB-1 & 14 & $0 \cdot 42$ & $16 \cdot 6$ & 31 & 2 & $1 \cdot 5 D, 2 D, 2 \cdot 5 D, 3 D, 5 D, 10 D$ \\
SC-SB-2 & 12 & $0 \cdot 5$ & $16 \cdot 6$ & 31 & 2 & $1 \cdot 5 D, 2 D, 2 \cdot 5 D, 3 D, 5 D, 10 D$ \\
SC-SB-3 & 10 & $0 \cdot 6$ & $16 \cdot 6$ & 31 & 2 & $1 \cdot 5 D, 2 D, 2 \cdot 5 D, 3 D, 5 D, 10 D$ \\
SC-SB-4 & 8 & $0 \cdot 75$ & $16 \cdot 6$ & 31 & 2 & $1 \cdot 5 D, 2 D, 2 \cdot 5 D, 3 D, 5 D, 10 D$ \\
SC-SB-5 & 6 & 1 & $16 \cdot 6$ & 31 & 2 & $1 \cdot 5 D, 2 D, 2 \cdot 5 D, 3 D, 5 D, 10 D$ \\
SC-SB-6 & 6 & 2 & $16 \cdot 6$ & 31 & 2 & $1 \cdot 5 D, 2 D, 2 \cdot 5 D, 3 D, 5 D, 10 D$
\end{tabular}

aUC, uniform clay; US, uniform sand; SC, sand on clay; SB, smooth boundary; RB, rough boundary

Table 2. Summary of case studies in LDFE analyses 


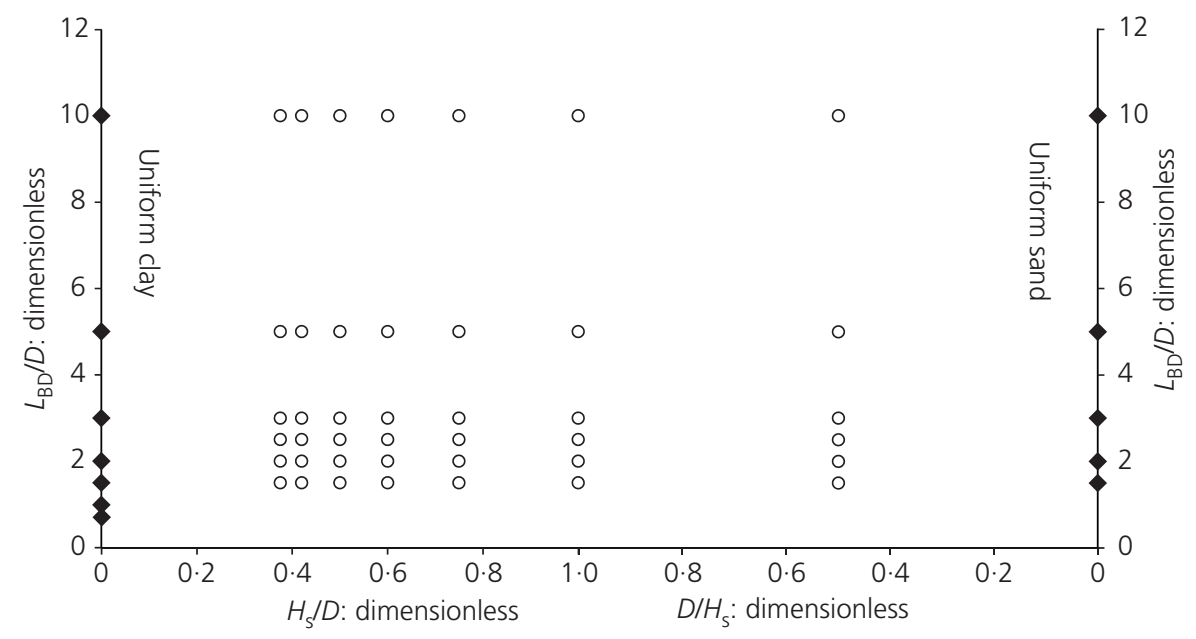

Figure 2. Summary of geometries studied

response, because it showed no difference compared with the results with a more distant boundary. Thus, the effect of the lateral boundary can be studied by comparing any other cases with the $L_{\mathrm{BD}} / D=10$ case.

As shown in Figure 2, the interim SC cases cover a sand thickness over diameter ratio $\left(H_{\mathrm{s}} / D\right)$ of $0 \cdot 375-2\left(D / H_{\mathrm{s}}=0 \cdot 5-2 \cdot 67\right)$, which are relevant to the cases commonly tested experimentally. The penetration reference point (point $P$ in Figure 1) in all the analyses presented is taken at the bottom widest area ( $A=\pi D^{2} / 4$ ) of the spudcan where the nominal bearing resistance, $q_{\text {nom }}$ is defined as the net vertical load ( $F_{\text {net }}=F_{\text {total }}-F_{\text {buoyancy }}$ ) divided by the widest spudcan area $\left(q_{\text {nom }}=F_{\text {net }} / A\right)$.

The $2 D$ axisymmetric triangular elements with six nodes and three internal gauss points were used in all the analyses, taking advantage of the near-axisymmetric geometry of spudcan foundations.

The Mohr-Coulomb (MC) model was used for sand simulation with fully drained behaviour. Only loose sand with a friction angle $(\phi)$ of $31^{\circ}$ and a small dilatancy angle $(\psi)$ of $2^{\circ}$ was used in all the analyses. This is due to the inherent limitation of the current MC model used for sand, which is unable to model the softening response of dense sand after peak resistance is encountered. For numerical stability, a small amount of cohesion $(c)$ of $0 \cdot 1 \mathrm{kPa}$ was used for sand. Poisson's ratio $(v)$ adopted for the sand was $0 \cdot 20$ and Young's modulus of elasticity $E$ was $24 \mathrm{MPa}$ to represent loose sand (Das, 2010) and the effective unit weight $\left(\gamma_{\mathrm{s}}^{\prime}\right)$ was $11 \mathrm{kN} / \mathrm{m}^{3}$. The earth pressure coefficient at rest $\left(K_{0}\right)$ for sand was calculated using a simplified form of Jaky's expression $\left(K_{0}=1-\sin \phi\right)$. To study the effect of Poisson's ratio of sand, two small-strain analyses were performed for loose sand $\left(I_{\mathrm{D}}=44 \%, H_{\mathrm{s}}=3.2 \mathrm{~m}, D=8 \mathrm{~m}\right.$, $\phi=31^{\circ}, \psi=3 \cdot 3^{\circ}$ ) overlying soft clay (undrained shear strength $s_{\mathrm{u}}=11.01 \mathrm{kPa}$ with a strength gradient of $1.55 \mathrm{kPa} / \mathrm{m}$ ) stratigraphy (Figure 3 ). The geometry and material properties correspond to test L3SP2 reported in $\mathrm{Hu}$ et al. (2014) with the friction and dilation angles in the MC model calculated according to the modified form of Bolton's (1986) equations

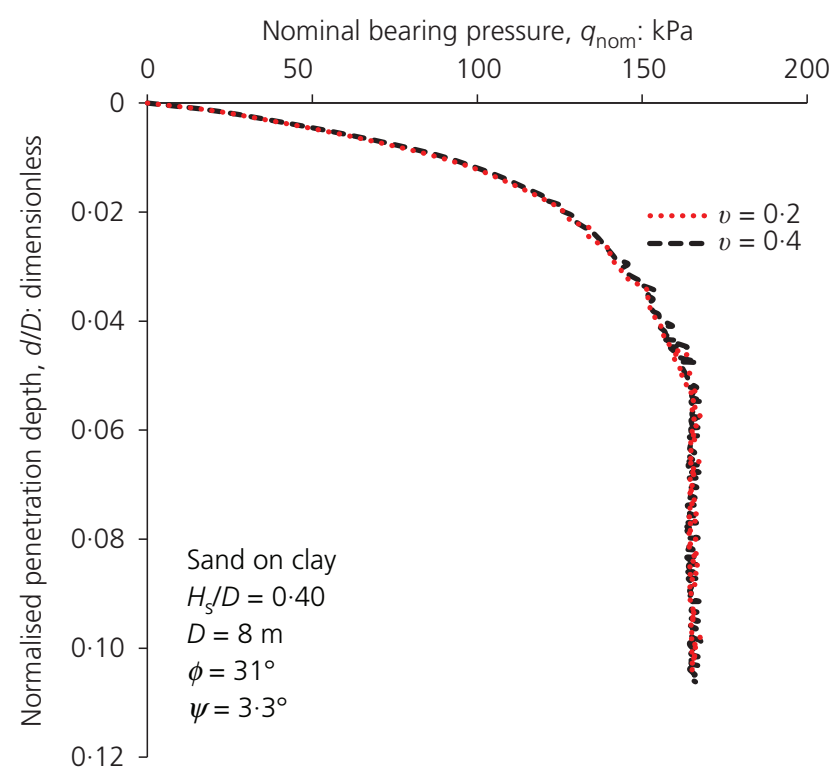

Figure 3. Effect of Poisson's ratio $(v)$ on the peak capacity of a loose sand over clay soil 
International Journal of Physical Modelling in Geotechnics Volume 17 Issue 3
Lateral boundary effects in centrifuge

foundation tests

Ullah, Hu, Stanier and White as given in Lee et al. (2013). The results indicate that Possion's ratio $(v)$ over the range of $0 \cdot 2-0 \cdot 4$ commonly adopted for sand has no impact on the measured load-penetration response.

For the normally consolidated clay soil, the MC model with the friction angle $(\phi)$ and dilation angle $(\psi)$ both taken as $0^{\circ}$ - equivalent to the Tresca failure criterion - was applied to model the undrained behaviour. Uniform undrained shear strength $\left(s_{\mathrm{u}}\right)$ of $16.6 \mathrm{kPa}$ was applied for the clay representing soft marine clay. A uniform stiffness ratio, $E / s_{\mathrm{u}}$ of 350 was chosen, which falls within the range expected for soft clay (Das, 2010). Poisson's ratio (v) was taken as 0.49 to minimise volume change during shear while maintaining numerical stability. The effective unit weight of clay $\left(\gamma_{\mathrm{c}}^{\prime}\right)$ was taken as $6.5 \mathrm{kN} / \mathrm{m}^{3}$ which is within the range commonly reported for the University of Western Australia and Malaysian kaolin clay tested extensively in the centrifuge (Stewart, 1992; Teh et al., 2010). The earth pressure coefficient at rest for clay was taken as unity $\left(K_{0}=1 \cdot 0\right)$. The spudcan soil interface was modelled as fully rough in all the analyses presented here, as it is assumed to be the case most susceptible to lateral boundary effects.

The spudcan was modelled as rigid. Elastoplastic nodal joint elements were used to model the soil-structure interaction between the spudcan and the soil in contact with it. A pair of nodes (one from the soil and the other of the foundation) was

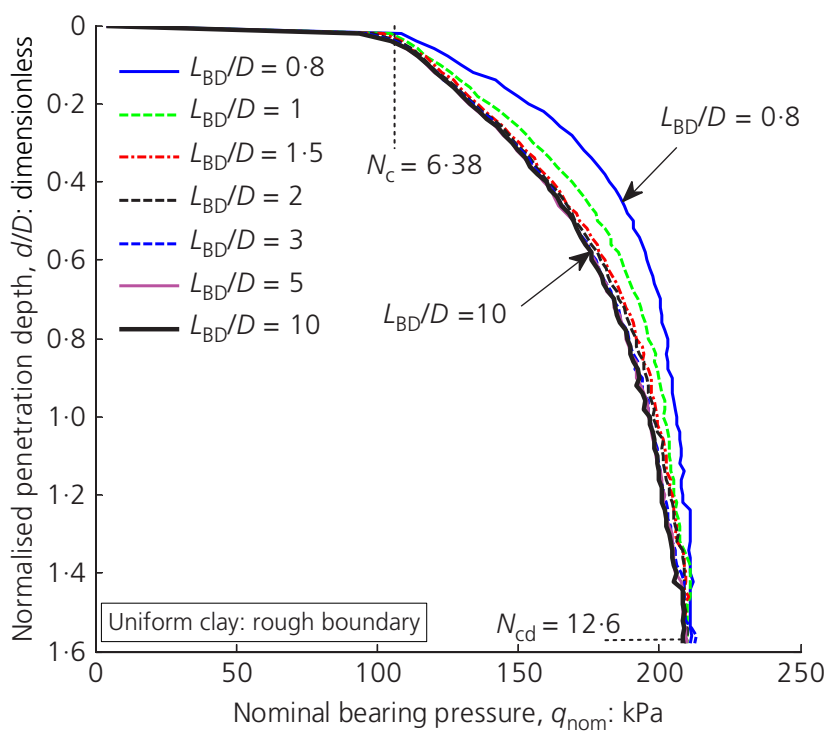

(a)

Figure 4. Effect of lateral boundary on penetration response in UC: (a) RB and (b) SB placed at the same initial location connected with normal and shear springs (an illustrative sketch of the nodal joint elements can be found in Yu et al., 2012). The stiffness of the normal spring was kept very high to avoid any soil penetration into the foundation. The MC model friction law controlled the shear strength of the shear slider. A fixed prescribed displacement loading increment was applied in all the analyses. Following $\mathrm{Hu}$ et al. (1999), the remeshing step $(N)$ and displacement increment $(\delta)$ were chosen such that $N \delta<0 \cdot 5 h_{\min }$, where $h_{\min }$ is the minimum element size. The small-strain analysis between each remeshing was conducted using a finite element numerical algorithm (AFENA) (Carter and Balaam, 2006), which was developed at the University of Sydney. To reach an optimum mesh and minimise discretisation error, $h$-refinement cycles were implemented as suggested by $\mathrm{Hu}$ and Randolph (1998b).

\section{Lateral boundary effect in single soil layer}

\subsection{Single layer of UC}

The effect of RB on the load penetration response of spudcan foundation in UC (case UC-RB of Table 2) is depicted in Figure 4(a). By comparing with the case of $L_{\mathrm{BD}} / D=10$, it is observed that the spudcan capacity is increased with decreasing boundary distance $L_{\mathrm{BD}}$. However, this effect diminishes when the spudcan penetration reaches $1.5 \mathrm{D}$. At very shallow penetration $(d / D<0 \cdot 1)$, unless the boundary is very close, there is

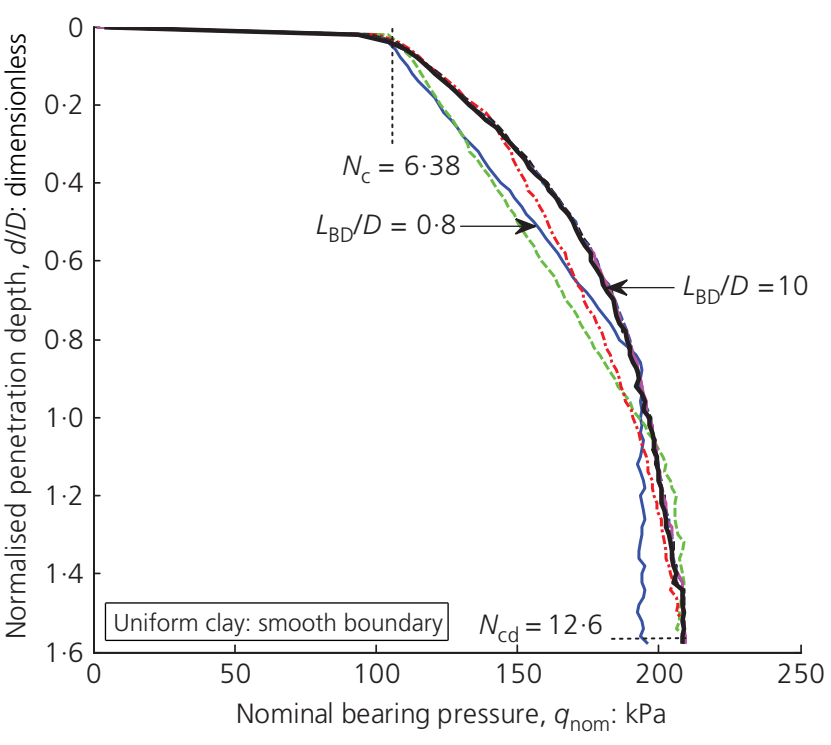

(b) 
International Journal of Physical Modelling in Geotechnics Volume 17 Issue 3
Lateral boundary effects in centrifuge

foundation tests

Ullah, Hu, Stanier and White minimal soil-boundary interaction with soil displacements confined around the foundation resulting in negligible boundary effects (the same explanation applies to US as described shortly). The surface footing capacity is conventionally calculated at a shallow penetration depth of $d / D=0 \cdot 1$ as $q_{\text {nom }}=106 \mathrm{kPa}$, which gives $N_{\mathrm{c}}=q_{\mathrm{nom}} / s_{\mathrm{u}}=6 \cdot 38$. This is only $1.7 \%$ greater than the lower-bound plasticity solution of Houlsby and Martin (2003) $\left(N_{\mathrm{c}}=6 \cdot 27\right)$. The largest effect from the close boundary is observed at penetration around $d / D$ of $0 \cdot 4$. At about $d / D=1 \cdot 5$, the spudcan penetration resistance converges to that of $L_{\mathrm{BD}} / D=10$ case. This demonstrates that once $L_{\mathrm{BD}} / D \geq 1 \cdot 5$, the boundary effect is minimal and can be ignored.

A small jump was recorded in all the load-penetration curves (e.g. at $d / D=1.2$ for $L_{\mathrm{BD}} / D=0 \cdot 8$ ). Craig and Chua (1990) also reported similar jumps in centrifuge tests performed in uniform submerged clay (Figure 7, $s_{\mathrm{u}}=29 \mathrm{kPa}$ case of Craig and Chua, 1990). This jump marks the closure of the full open cavity formed above the spudcan (Hossain et al., 2004). Beyond this jump a steady-state response is achieved without noticeable increase in resistance gradually attaining a fulllocalised flow around the spudcan. Interestingly, this jump can be found around $d / D=1.4$ for $L_{\mathrm{BD}} / D=3-10$ cases. For $L_{\mathrm{BD}} / D=1,1.5$ and 2 cases this occurred at $d / D=1 \cdot 3$. Hence, placing the RB very close to the foundation encourages more soil to flow into the open cavity causing a deep localised flow to occur earlier.

Figure 4(b) reports the spudcan penetration responses in UC with smooth side boundaries (case UC-SB of Table 2). As opposed to cases with rough boundaries, the spudcan penetration resistance decreases when the $\mathrm{SB}$ distance is $<2 D$. This is because the SB makes the upward soil flow easier compared with an RB or an infinite soil domain. The general curvilinear responses, which are observed for $L_{\mathrm{BD}} / D \geq 2$ with an $\mathrm{SB}$ and for all with an $\mathrm{RB}$, are replaced by somewhat segmented linear responses for $L_{\mathrm{BD}} / D \leq 1.5$ with an SB. All the curves converge to the deep bearing capacity $\left(N_{\mathrm{cd}} \times s_{\mathrm{u}}\right)$ when the penetration depth $d / D>1 \cdot 5$, except the case with $L_{\mathrm{BD}} / D=0 \cdot 8$.

The deep penetration bearing capacity factor $\left(N_{\mathrm{cd}}=q_{\mathrm{nom}} / s_{\mathrm{u}}\right)$ at $d / D$ of 1.58 for the rough spudcan studied here is obtained as $N_{\text {cd }}=12.60$ from the $L_{\mathrm{BD}} / D=10$ case, where the lateral boundary effect is minimal. This is only $3 \cdot 8 \%$ lower than LDFE simulations of Hossain and Randolph (2009) and plasticity solutions of a deeply buried rough thin plate (Martin and Randolph, 2001). Penetration beyond $d / D$ of 1.6 might further narrow this gap.

On the basis of the above discussions, the distance that the lateral boundary needs to be placed to eliminate the boundary effect for uniform soft clay can be deduced as $L_{\mathrm{BD}} / D=1.5$ for an $\mathrm{RB}$ and $L_{\mathrm{BD}} / D=2.0$ for an $\mathrm{SB}$. Where the boundary is placed closer than the minimum distance, the spudcan resistance is increased with an RB and decreased with an SB due to the influence of the boundary proximity and roughness. The largest boundary effect occurs at penetration depth $d / D \sim 0.4$. The cavity depth above the penetrating spudcan in clay has been studied by Hossain et al. (2004) and increases with increasing dimensionless soil strength $\left(s_{\mathrm{u}} / \gamma_{\mathrm{c}}^{\prime} D\right)$. Since cavity expansion occurs when the cavity is formed above the spudcan during penetration, and localised soil flow occurs when deep penetration is achieved (Hossain et al., 2004), the boundary effect is more profound during cavity expansion mode. The boundary effect on bearing capacity becomes minimal when $d / D>1.5$ for all cases, except $L_{\mathrm{BD}} / D=0 \cdot 8$, where the $\mathrm{SB}$ is very close to the foundation.

\subsection{Single layer of US}

Figures 5(a) and 5(b) report the penetration response in US for rough and smooth lateral boundaries, respectively (cases US-RB and US-SB of Table 2). All results display a steady increase in bearing resistance with continuous spudcan penetration. This overall trend is similar to that observed in loose sand by Craig and Chua (1990).

For the RB case (Figure 5(a)), the lateral boundary had a consistent impact on resistance with a smaller $L_{\mathrm{BD}}$ increasing the resistance significantly. Although the impact was smaller at shallow penetration, the resistance curves diverged from the $L_{\mathrm{BD}} / D=10$ case with deeper penetration. With increasing $L_{\mathrm{BD}} / D$ from 1.5 to 5 , the resistance curves shift towards the $L_{\mathrm{BD}} / D=10$ case in a sequential manner. For $L_{\mathrm{BD}} / D=5$, the boundary has almost no influence on resistance.

When the lateral boundary is smooth (Figure 5(b)), the boundary effect on the spudcan resistance is not as significant as that caused by the RB. However, the trend of the boundary effect is inconsistent. When the boundary is placed at $L_{\mathrm{BD}} / D=1 \cdot 5$, the spudcan resistance is increased when $d / D<0 \cdot 7$; and decreased when $d / D>0 \cdot 7$. Although the boundary effect is minimal when $L_{\mathrm{BD}} / D=5$, a marginal increase $(\sim 5 \%)$ in spudcan resistance is still present as $d / D>1 \cdot 0$. This inconsistent trend in boundary effect could be due to the absence of friction on the lateral boundary. When the lateral boundary is close to the spudcan, the restriction of soil lateral movement would push the soil upwards, generating more surface heave and consequently higher spudcan penetration resistance. At the same time, the SB makes such upward movement easier, reducing spudcan penetration resistance. Thus, the boundary effect is influenced by the counteracting effects from soil heave and by the absence of vertical resistance from the wall, as discussed later. For the loose sand studied here, the recommended minimum boundary distance is $L_{\mathrm{BD}} / D=5$. 


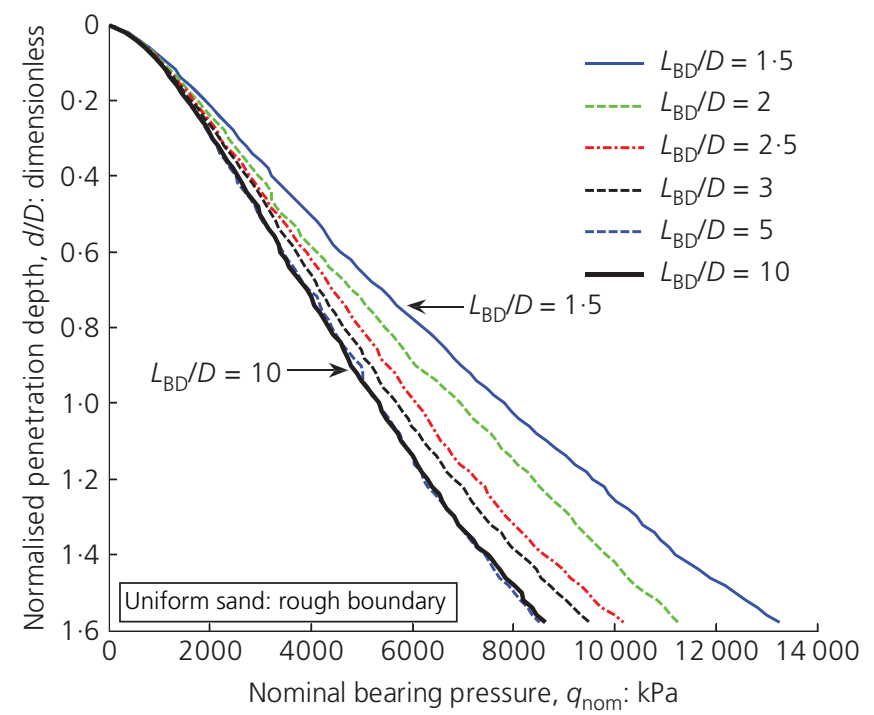

(a)

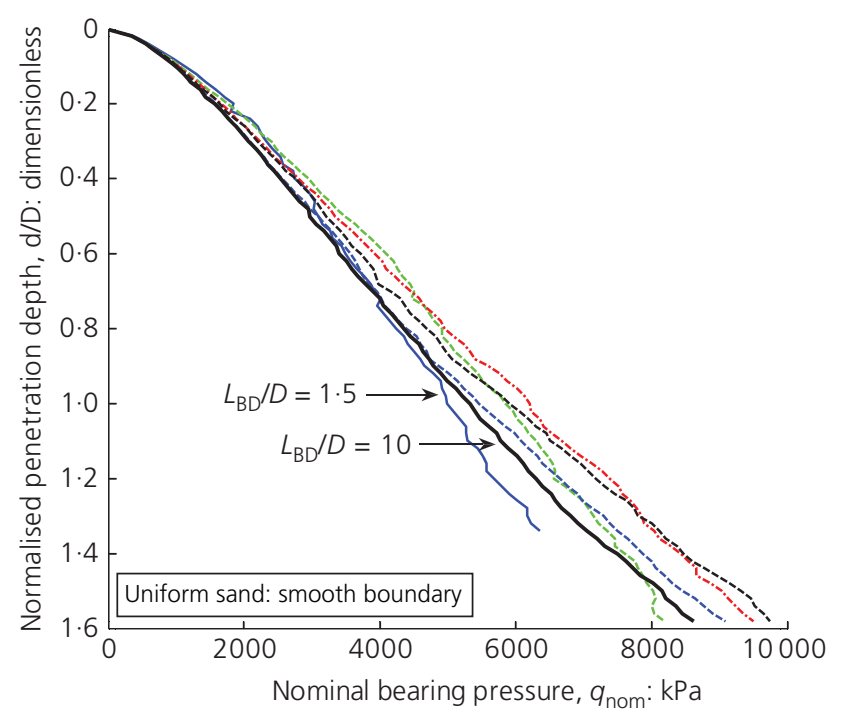

(b)

Figure 5. Effect of lateral boundary on penetration response in US: (a) RB and (b) SB

\section{Lateral boundary effect on sand over clay soils}

\subsection{Single against double soil layers}

Figure 6 depicts the comparison between the spudcan penetration responses in single and double soil layers. The responses presented are for a $D=10 \mathrm{~m}$ spudcan with normalised sand layer thickness $H_{\mathrm{s}} / D=0.6$ for the $\mathrm{SC}$ case. The normalised lateral boundary distance was set as $L_{\mathrm{BD}} / D=10$, hence the boundary effects can be neglected. For a comparative study, the sand and clay properties in all the stratigraphies are the same with the material properties listed in Table 2 . As can be readily observed, the spudcan bearing capacity is the lowest in UC and the highest in US; the SC case falls in between these bounds.

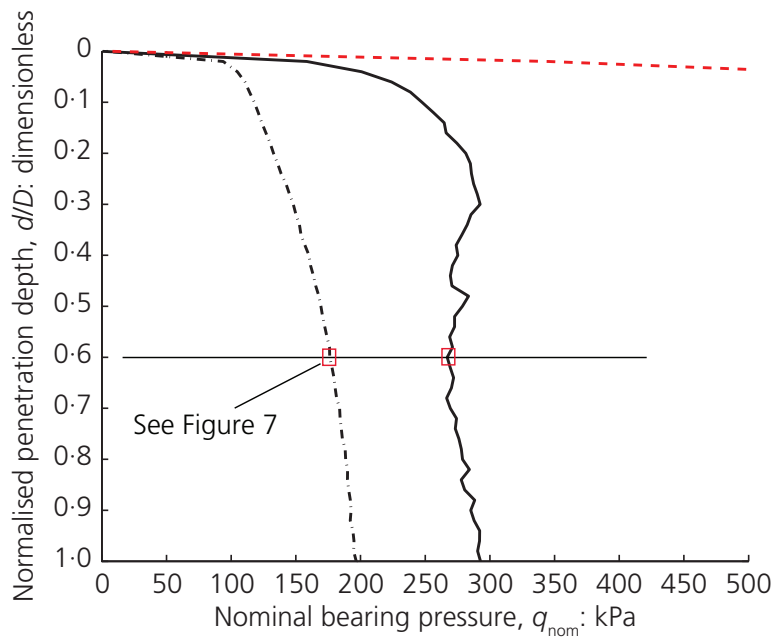

(a)

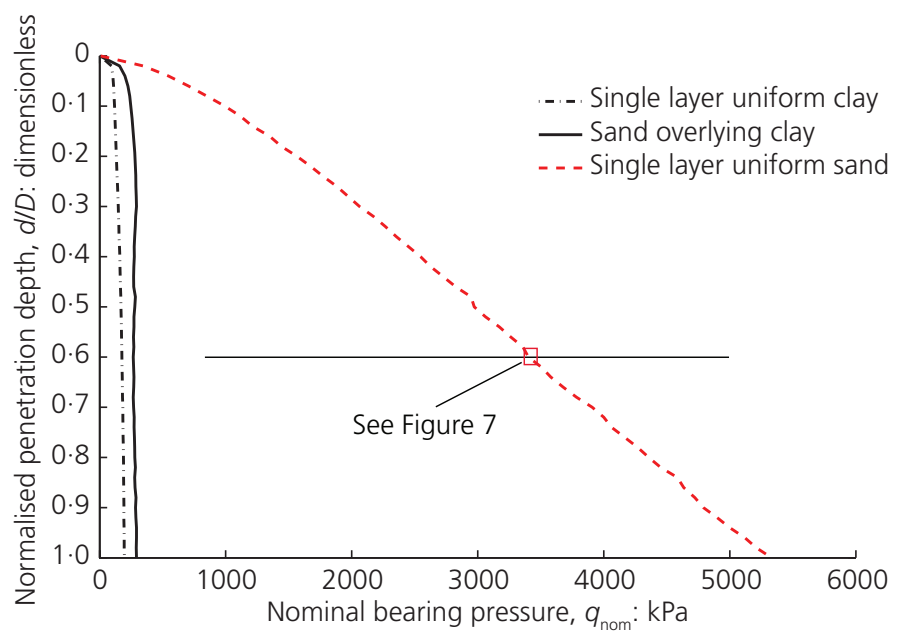

(b)

Figure 6. Typical load-penetration responses in uniform and layered stratigraphies 
International Journal of Physical Modelling in Geotechnics Volume 17 Issue 3
Lateral boundary effects in centrifuge

foundation tests

Ullah, Hu, Stanier and White
At a normalised penetration depth $(d / D)$ of $0 \cdot 6$, the nominal resistance of $\mathrm{UC}$ is $\sim 180 \mathrm{kPa}$. At the same penetration depth, the spudcan capacity is 1.5 times higher for SC and almost 20 times higher in US. As the sand strength increases with increasing effective stress level, a higher resistance in US is expected. Using the equations provided by Hansen (1970), the US bearing capacity at $d / D=0.60$ is calculated to be $\sim 3000 \mathrm{kPa}\left(\phi=31^{\circ}, N_{q}=20.63\right.$ and $N_{\gamma}=17 \cdot 69$, where $N_{q}$ and $N_{\gamma}$ are the sand bearing capacity factors due to the surcharge and weight, respectively) compared with $\sim 3400 \mathrm{kPa}$ in the FE analysis. For the SC case, a sand plug with depth close to the sand height was entrapped beneath the spudcan and remained practically unchanged with penetration into the bottom clay (Figure 7). For SC, the additional bearing capacity mobilised beyond the sand-clay interface can be attributed to this plug, which now acts as part of the foundation and generates bearing resistance along its periphery (Craig and Chua, 1990).

The soil flow mechanism at $d / D=0 \cdot 6$ is compared for all the three soil profiles in Figure 6. An open cavity is observed in UC, whereas a wall-type failure is evident for both SC and US. Qiu and Henke (2011) also observed similar wall-type failure in their LDFE analysis. A marked surface heave is noticeable in UC, whereas a lack of cohesion forces sand to flow back on top of the advancing spudcan in SC and US cases. Rotational flow into the open cavity is seen in UC, which will eventually cause the cavity to collapse with further penetration (Hossain et al., 2005).

For the SC soil case, the entrapped plug moved vertically downwards with the spudcan. The clay below the sand plug flows around the plug and the sand-clay interface is deformed. The rotational flow mechanisms observed in UC are not observed in US, with the different mechanisms leading to different scales of boundary effect.

\subsection{Effect of sand layer thickness}

\subsubsection{RB (cases SC-RB-0 to SC-RB-6 of Table 2)}

Figure 8 displays the load-penetration responses on SC soil for an RB with $H_{\mathrm{s}} / D$ varying from $0 \cdot 375$ to 2 . It can be seen that the boundary effect increases with increasing top sand layer thickness. For the sand layer thickness $H_{\mathrm{s}} / D \geq 1 \cdot 0$ (Figures 8 (b) and $8(\mathrm{c})$ ), the rough lateral boundary affects the spudcan response in the whole sand layer. When the top sand layer thickness is reduced to $H_{\mathrm{s}} / D=0.6$ (Figure $8(\mathrm{~b})$ ), the boundary effect is restricted to the shallow penetration (up to $d / D=0 \cdot 3$ ). Once the top sand layer thickness is as thin as $H_{\mathrm{s}} / D=0 \cdot 375$ (Figure $8(\mathrm{a})$ ), the effect of the boundary is minimal, although a slight increase in foundation capacity can be observed at very shallow penetration (up to $d / D=0 \cdot 2$ ).

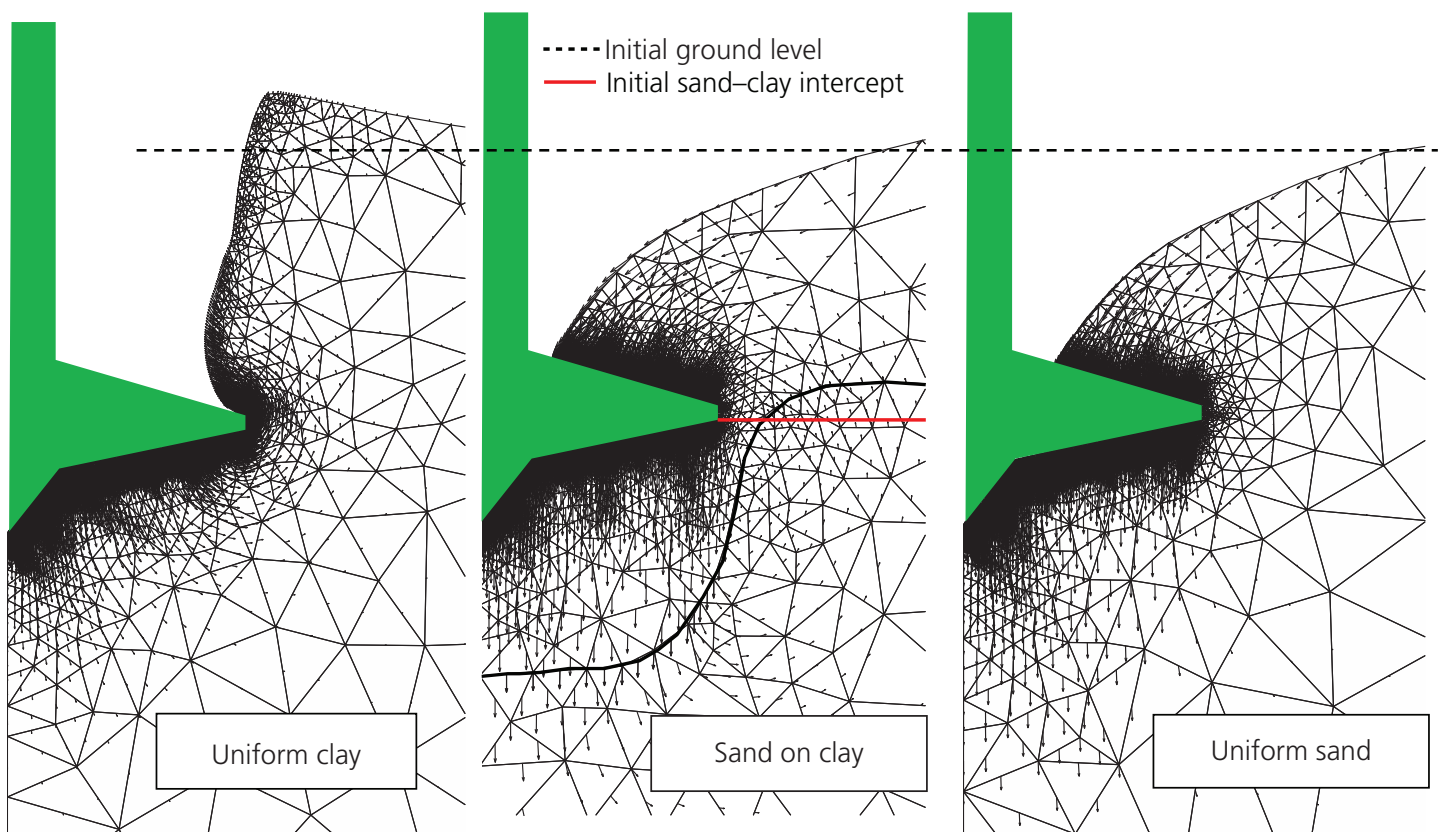

Figure 7. Typical soil flow mechanisms in uniform and layered stratigraphies at $d / D=0.60$ 


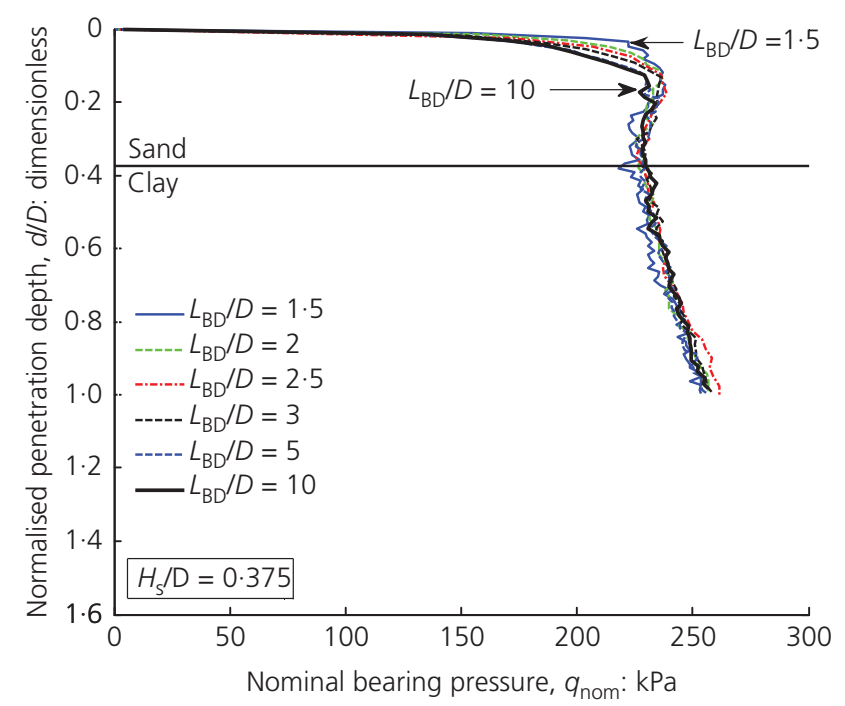

(a)

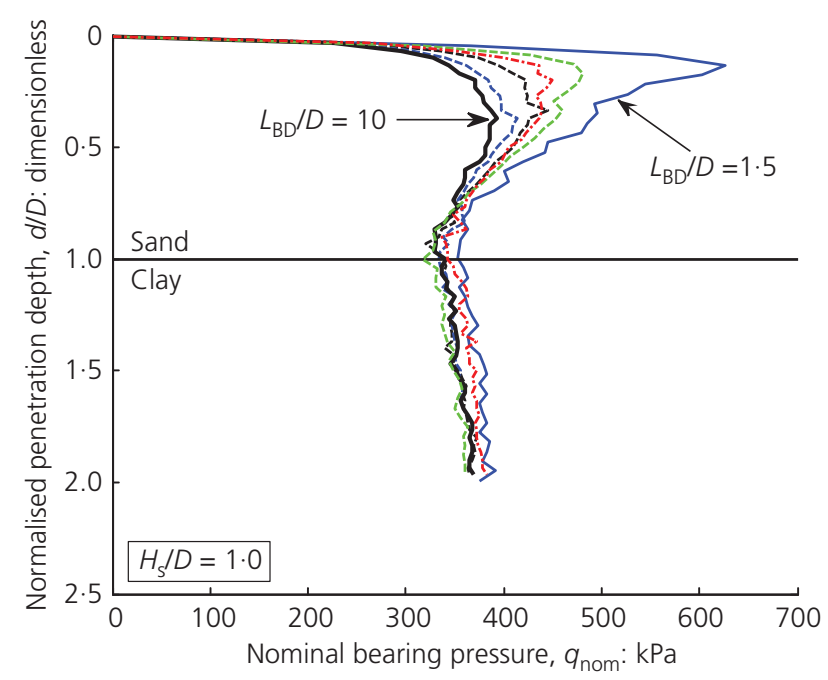

(c)

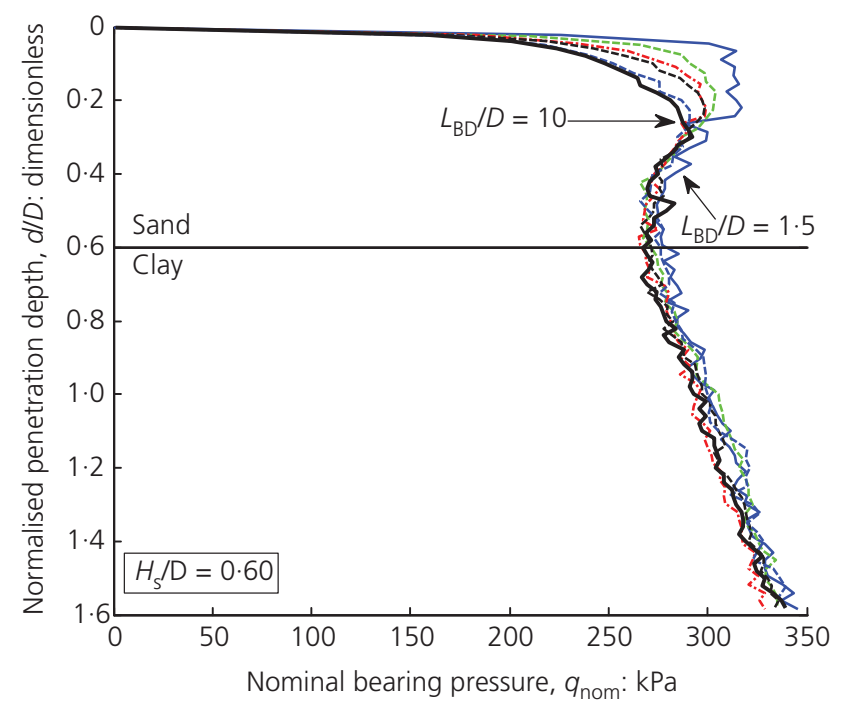

(b)

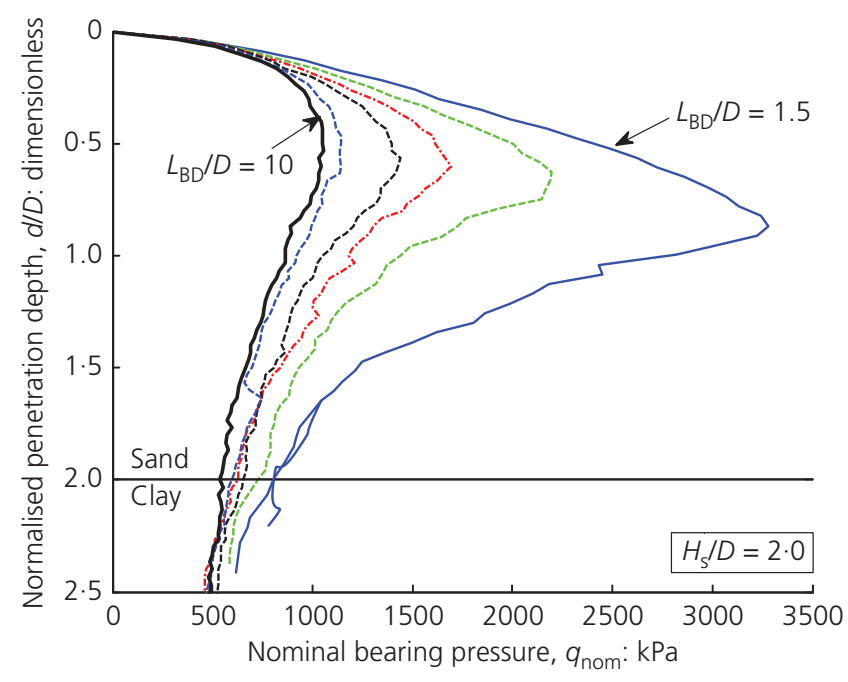

(d)

Figure 8. Effect of rough lateral boundary on measured penetration resistance for SC stratigraphies: (a) $H_{s} / D=0.375$;

(b) $H_{s} / D=0.6$; (c) $H_{s} / D=1 \cdot 0$; and (d) $H_{s} / D=2 \cdot 0$

The close proximity of a rough lateral boundary and thicker overlying sand layers leads to increased peak bearing capacity $\left(q_{\text {peak }}\right)$ relative to the $L_{\mathrm{BD}} / D=10$ case. This is because a thicker top sand layer generates a larger sand plug underneath the spudcan, which needs to be pushed into the bottom clay layer; at the same time a closer $\mathrm{RB}$ requires more effort to push the sand heave upwards. After mobilising the peak capacity $\left(q_{\text {peak }}\right)$, the spudcan capacity gradually converges to the response of $L_{\mathrm{BD}} / D=10$ case as penetration progresses deeper into the clay. As the spudcan and underlying sand plug penetrates into the clay layer, a rotational flow mechanism develops which has also been observed experimentally (Teh et al., 2008). Hence, as the soil failure mechanism gradually changes from the sand spreading mechanism during the peak and to the full flow-around mechanism in clay, the requirement of normalised lateral boundary distance $\left(L_{\mathrm{BD}} / D\right)$ reduces, since the boundary effect for spudcan penetrating deeply into the clay is minimal (see $d / D>1 \cdot 2$ in Figure 4(a)).

In summary, for all the RB cases analysed here, a closer boundary increases the spudcan peak resistance in sand in proportion to the sand layer thickness; thus the thicker the sand 
Lateral boundary effects in centrifuge

foundation tests

Ullah, Hu, Stanier and White layer being modelled, the larger the strongbox required. The strongbox size has minimal effect on spudcan penetration resistance in the bottom clay layer.

\subsubsection{SB (cases SC-SB-0 to SC-SB-6 of Table 2)}

Figure 9 reports on the corresponding load-penetration responses of a spudcan in a strongbox with a smooth lateral boundary. Although the sand layer thickness affects spudcan peak resistance, the SB has more influence on spudcan resistance after the peak. In contrast to the RB case, placing an SB close to the spudcan (i.e. $L_{\mathrm{BD}} / D=1.5$ ) decreases $q_{\text {peak }}$ compared with the $L_{\mathrm{BD}} / D=10$ case for $H_{\mathrm{s}} / D \leq 1$. This is because a punching shear failure is expected for a thin sand layer. Vertical soil movement dominates in the punching shear mechanism and a smooth lateral boundary allows easy sliding of soil along the boundary (Figure 10).

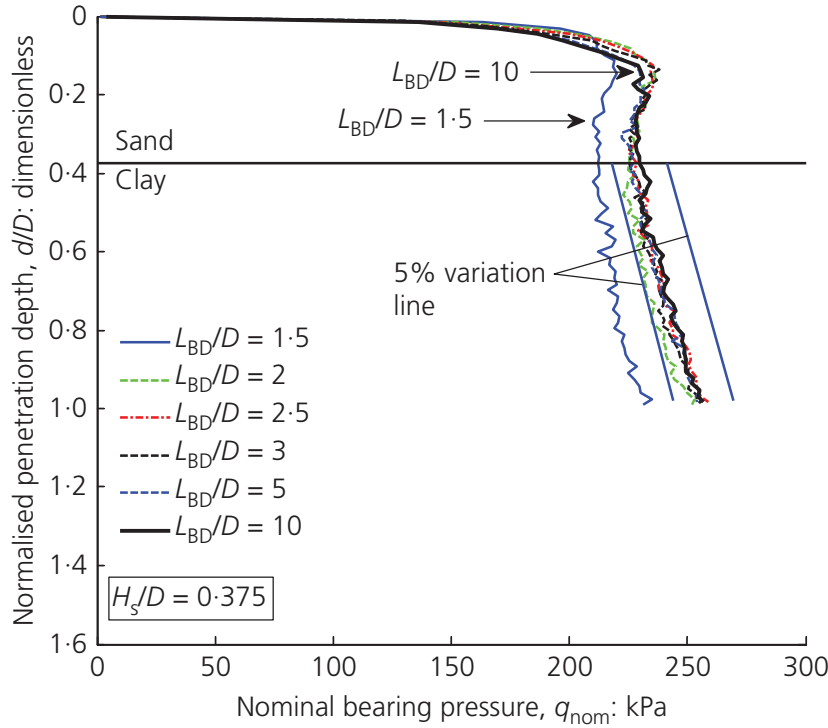

(a)

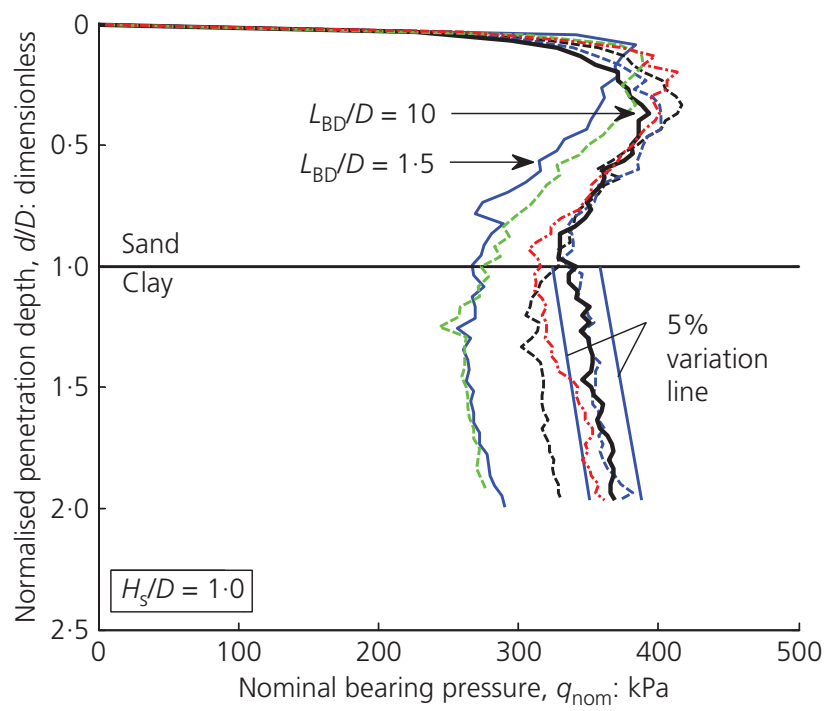

(c)

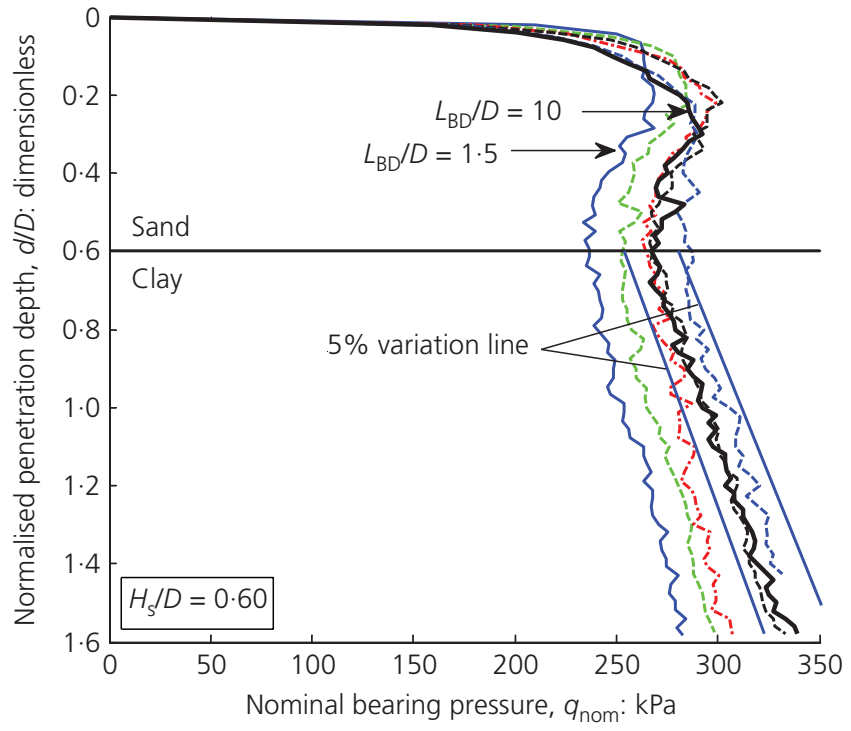

(b)

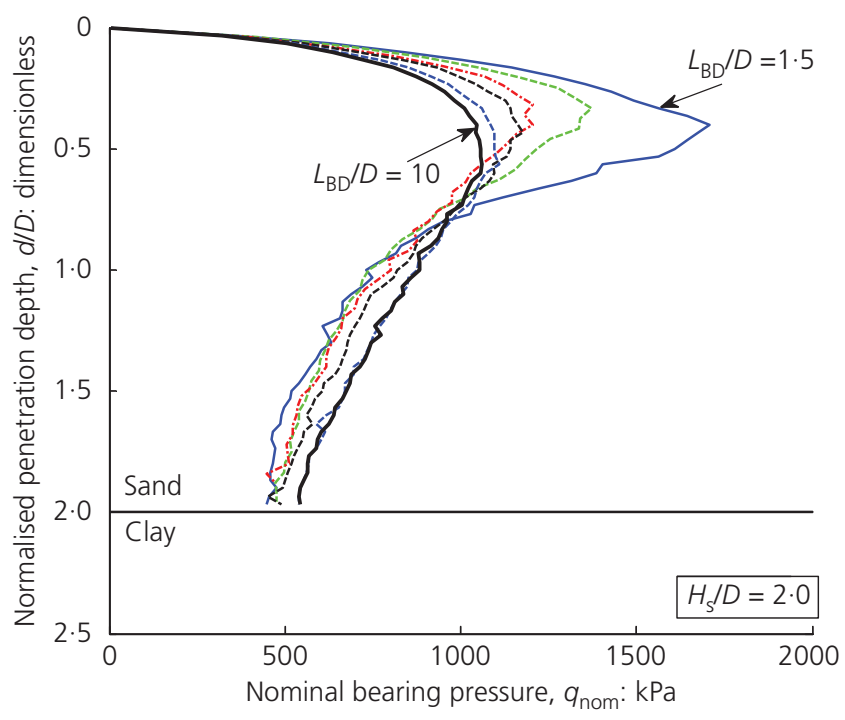

(d)

Figure 9. Effect of smooth lateral boundary on measured penetration resistance for SC stratigraphies: (a) $H_{s} / D=0.375$; (b) $H_{s} / D=0.6$; (c) $H_{s} / D=1.0$; and (d) $H_{s} / D=2 \cdot 0$ 

Volume 17 Issue 3

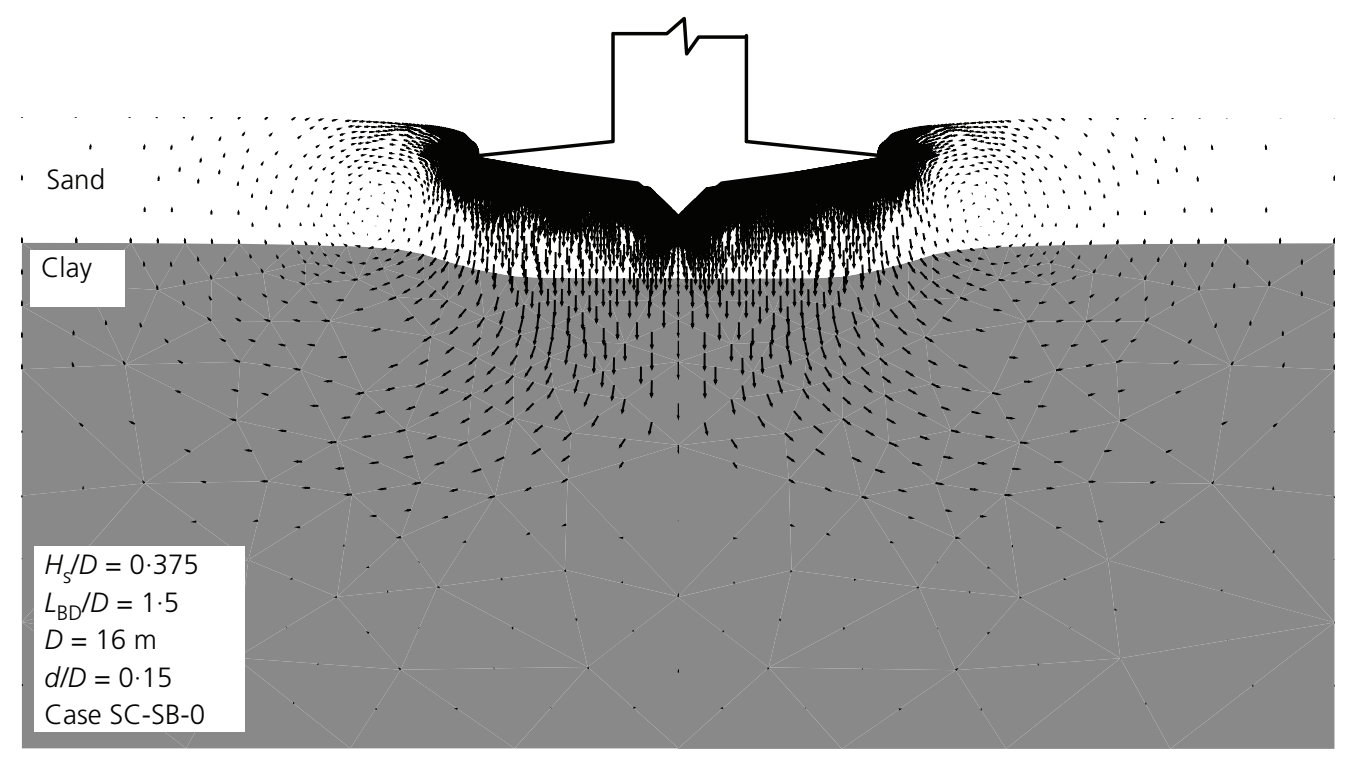

Figure 10. Soil vectorial displacements at peak resistance for a thin sand layer overlying clay with narrow boundary distance (case SC-SB-0 in Table 2)

For a thicker sand layer $\left(H_{\mathrm{s}} / D=2\right.$ or $D / H_{\mathrm{s}}=0 \cdot 5$, Figure $\left.9(\mathrm{~d})\right)$, the peak resistance increases with decreasing normalised lateral boundary distance $L_{\mathrm{BD}} / D$, although the lateral boundary is smooth, implying that a close lateral boundary restricts the lateral displacement of sand. This restriction dominates the bearing behaviour of spudcan (Figure 11). Therefore, the trend of spudcan peak resistance against normalised lateral boundary distance $\left(L_{\mathrm{BD}} / D\right)$ is the same as the RB (Figure $8(\mathrm{~d})$ ), but with a lower magnitude due to the SB.

As penetration progressed deeper into the bottom clay, the curves no longer merge together, as was the case for the RB. This is because the SB does not force the soil to flow fully around the foundation, as would have been the case if the boundary were rough or if it was remote. Instead, the soil tends to move towards the boundary and flow upwards rather than flowing rotationally on to the top of the foundation, because this offers lower resistance.

This behaviour under an SB introduces complexity in terms of choosing minimum strongbox dimensions. As in the rough case where the different $L_{\mathrm{BD}}$ curves tend to merge together with deeper penetration, only $q_{\text {peak }}$ (where differences were pronounced) was sufficient to identify a suitable $L_{\mathrm{BD}} / D$. On the other hand, although the extent of variation of $q_{\text {peak }}$ is smaller for an SB compared with the rough case, the deep resistance also varies compared with the $L_{\mathrm{BD}} / D=10$ curve (Figure 9).

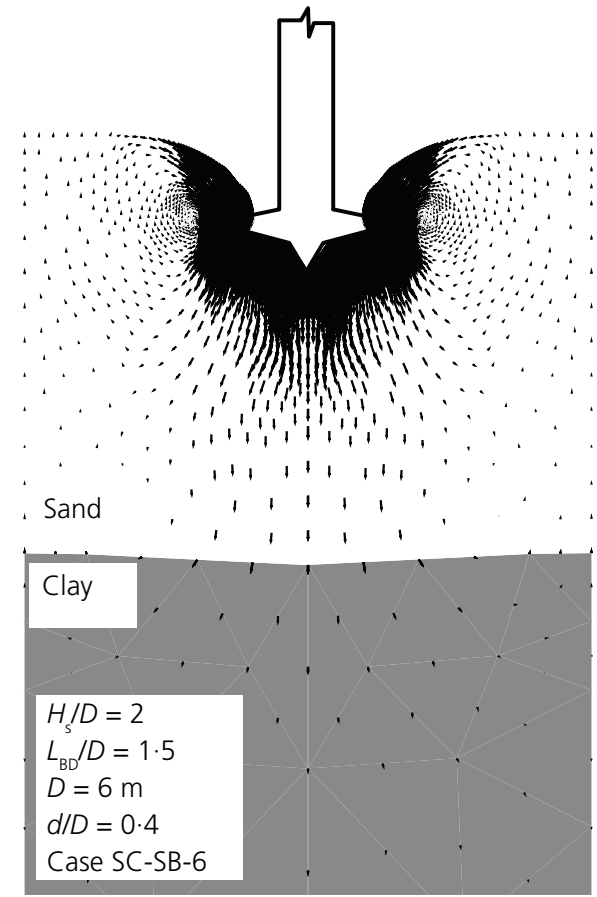

Figure 11. Soil vectorial displacements at peak for a thick sand layer overlying clay with narrow boundary distance (case SC-SB-6 in Table 2) 
International Journal of Physical Modelling in Geotechnics Volume 17 Issue 3
Lateral boundary effects in centrifuge

foundation tests

Ullah, Hu, Stanier and White
Hence, apart from $q_{\text {peak }}$, deep resistance variations must be considered when evaluating the suitability of strongbox dimensions for a given model test.

To this effect, $5 \%$ variation lines are plotted with respect to the resistance measured in the $L_{\mathrm{BD}} / D=10$ analysis on the $\mathrm{SB}$ resistance profiles (Figures 9(a)-9(c)), from the depth of the sand-clay interface to the deepest penetration recorded. These limiting lines are not plotted for the thicker sand case (Figure $9(\mathrm{~d})$ ) as the $L_{\mathrm{BD}} / D=5$ curve controls the $L_{\mathrm{BD}} / D$ requirement for both peak resistance and deep penetration. For deep penetration, the boundary distance should be taken as $L_{\mathrm{BD}} / D=2,3$ and 5 for $H_{\mathrm{s}} / D=0.375,0.6$ and 1 (Figures 9(a)-9(c)), respectively.

\subsection{Peak resistance ( $\left.q_{\text {peak }}\right)$}

Figure 12 collates the peak resistances of all the analyses performed for the layered soil (Figure 2 and Table 2) against the normalised lateral boundary distance $\left(L_{\mathrm{BD}} / D\right)$. In the vertical axis, the $q_{\text {peak }}$ for different soil profiles is normalised by that for $L_{\mathrm{BD}} / D=10$. Hence, a horizontal line passing through unity on the vertical axis represents the nil boundary effect line, while the $\pm 5 \%$ dotted line represents the variation caused by boundary proximity and roughness. Figures 12(a)-12(h) represent the $H_{\mathrm{s}} / D$ cases varying from 0 to 2 . The $H_{\mathrm{S}} / D=0$ case (Figure 12(a)) represents the UC case discussed before. For UC, since there is no peak resistance observed (Figure 4), the normalisation of resistance is chosen at penetration $d / D=0 \cdot 4$, where the most significant boundary effects were observed.

For $H_{\mathrm{s}} / D=2$, both SB and RB increase the peak capacity for reasons discussed earlier. For all other cases when the boundary wall was closer, the RB increased the resistance and the SB decreased it. As $H_{\mathrm{s}} / D$ reduces, the rough and smooth curves tend to converge. Hence, the boundary conditions have more influence on higher $H_{\mathrm{s}} / D$ ratios.

On the basis of the limiting boundary distance that would not exceed the $5 \%$ variation lines, the minimum $L_{\mathrm{BD}} / D$ for $H_{\mathrm{S}} / D=2$ with an RB (Figure $12(\mathrm{~h})$ ) can be taken as $5 \cdot 25$, for $\mathrm{SB}$ it is $4 \cdot 5$. Similarly for Figures $12(\mathrm{~b})-12(\mathrm{~g})$ the minimum $L_{\mathrm{BD}} / D$ can be measured accordingly. These values will contribute to the centrifuge test design chart presented later. For UC (Figure 12(a)) based on the $5 \%$ variation lines, the $L_{\mathrm{BD}}$ requirements are found to be lower than $L_{\mathrm{BD}}$ of $1.5 \mathrm{D}$ for rough and $2 D$ for smooth recommended earlier, as the resistance is least affected due to closeness of the boundary. However, as discussed before, smaller $L_{\mathrm{BD}}(<1 \cdot 5 D$ for rough or $2 D$ for smooth boundaries) might not reproduce the overall shape of the response observed when the boundary is remote (Figure 4).
To illustrate further the effect of lateral boundary, the shear stresses mobilised on the axisymmetric plane (1-2 plane) along a vertical line passing through the edge of the spudcan are compared in Figure 13, $z_{\mathrm{s}} / D$ is the normalised depth measured along this line. Figure 13(a) shows the comparison between the $L_{\mathrm{BD}} / D=10$ and 1.5 cases for an $\mathrm{RB}$ at penetration $d / D=0 \cdot 13$ and $H_{\mathrm{s}} / D=1$. The corresponding load-penetration response is shown in Figure $8(\mathrm{c})$, where at $d / D=0.13$ the $L_{\mathrm{BD}} / D=1.5$ curve mobilises peak resistance, but the $L_{\mathrm{BD}} / D=10$ curve needs to penetrate a little further to reach its peak.

The $\tau_{12}$ shows a similar trend for both $L_{\mathrm{BD}} / D=1.5$ and 10 cases but its magnitude is greater for the former. This explains the increased peak measured for $L_{\mathrm{BD}}=1 \cdot 5 \mathrm{D}$ in Figure 8(c). $\tau_{12}$ increases throughout the top sand layer, but starts to decrease near the sand-clay intercept when a weaker clay is encountered.

Figure 13(b) shows the same comparison for the smooth case, but now at $d / D=1.0$ where the differences were pronounced (Figure 9(c)). The $L_{\mathrm{BD}} / D=10$ case now mobilises greater resistance than the $L_{\mathrm{BD}} / D=1.5$ case. The sharp reduction of $\tau_{12}$ is noted near the clay, and is limited by the $s_{\mathrm{u}}=16.6 \mathrm{kPa}$ for clay.

\subsection{Surface heave}

The lateral boundary effect can be observed by its effect on the surface heave profile, where the upward movement is denoted as $\delta_{\text {heave }}$ Figures 14(a) and 14(b) compare the heave profile for the SC soil at $d / D=0.20$ for rough and smooth boundaries, respectively. The $H_{\mathrm{s}} / D$ is 0.60 and the loadpenetration responses are presented in Figures 8(b) and 9(b), respectively. The RB does not allow the boundary nodes to move which creates a sand dune-type profile. The $L_{\mathrm{BD}} / D=1 \cdot 5$ case recorded the maximum heave which decreases with increasing $L_{\mathrm{BD}} / D$. On the other hand, the $\mathrm{SB}$ places no restraint on the vertical movement of the lateral boundary nodes and hence no dune-type profile is observed (Figure 14(b)). As $L_{\mathrm{BD}} / D$ increases, the surface profiles gradually shift towards the $L_{\mathrm{BD}} / D=10$ profile.

\section{Design chart for centrifuge testing}

The final outcome of all the analyses performed is summarised in a design chart in Figure 15. The zones above and below the shaded region represent model geometries that will not and will likely be affected by boundary effects, respectively. The shaded region represents a zone where there is a potential for boundary effects, dependent on the boundary interface roughness condition. The layout and axes are the same as that shown in Figure 2, where the left and right vertical axes represent the UC and US cases, respectively. The intermediate values correspond to $\mathrm{SC}$ with different $H_{\mathrm{s}} / D$ and $D / H_{\mathrm{s}}$ ratios. Depending on the purpose and geometry of the test, 


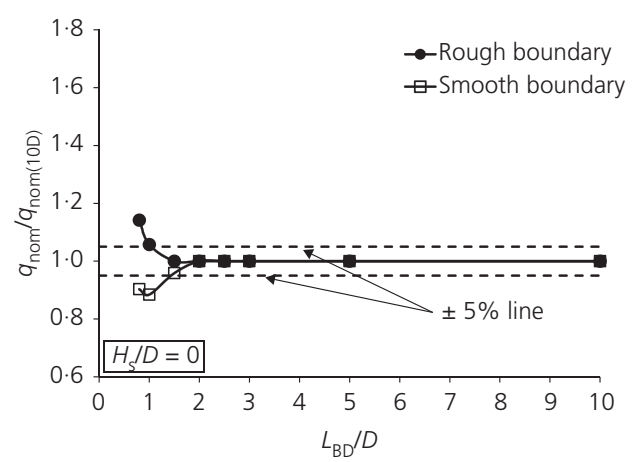

(a)

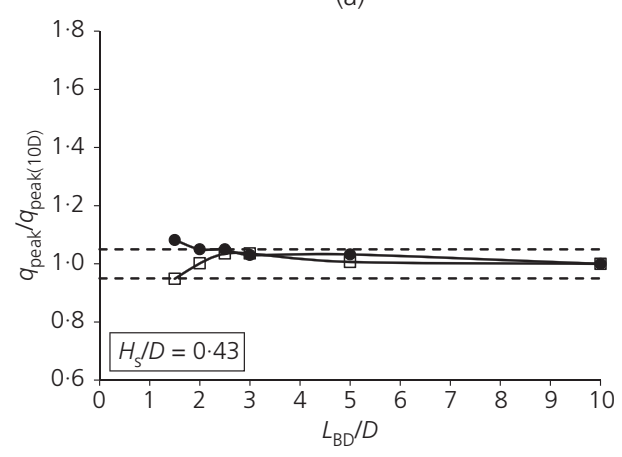

(c)

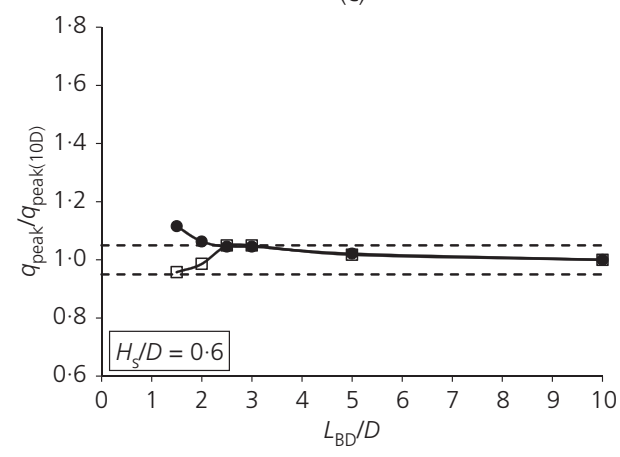

(e)

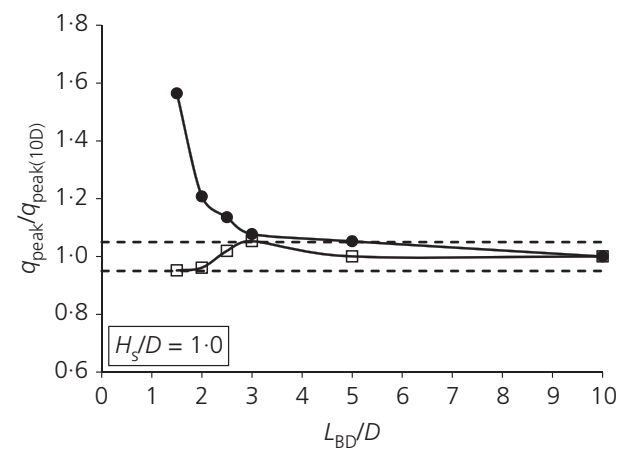

(g)

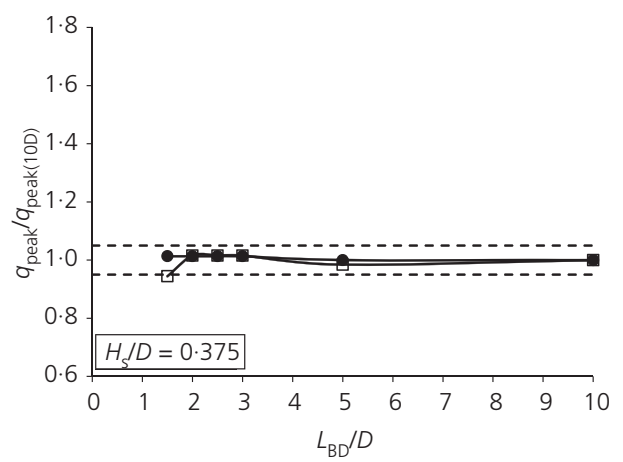

(b)

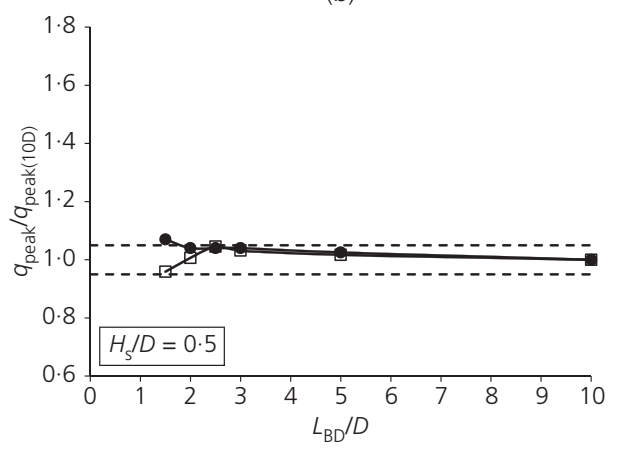

(d)

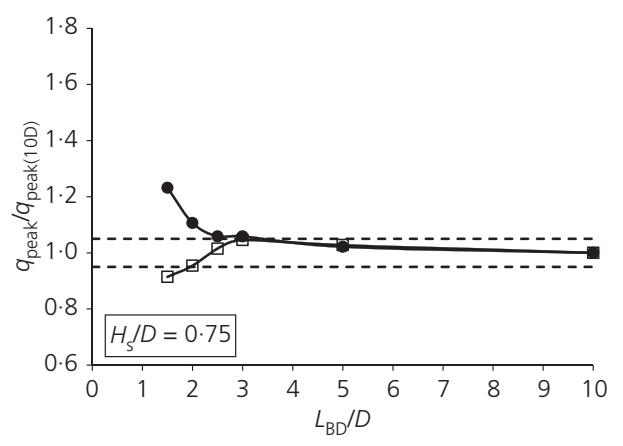

(f)

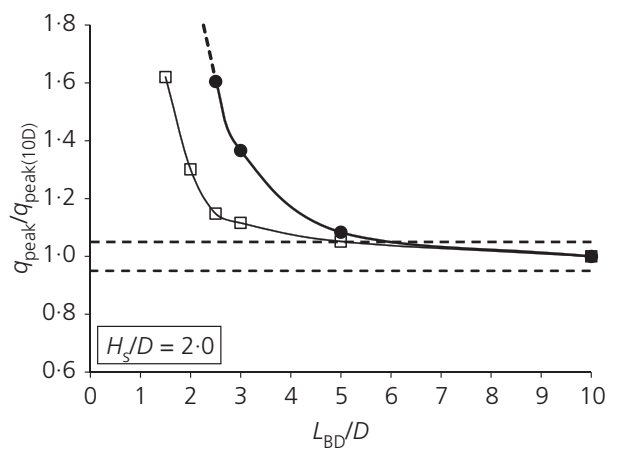

(h)

Figure 12. Normalised peak resistance $\left(q_{\text {peak }} / q_{\text {peak (10D) }}\right)$ against normalised lateral boundary distance $\left(L_{\mathrm{BD}} / D\right)$ : (a) $H_{\mathrm{s}} / D=0$;

(b) $H_{s} / D=0.375$; (c) $H_{s} / D=0.43$; (d) $H_{s} / D=0.50$; (e) $H_{s} / D=0.60$;

(f) $H_{s} / D=0.75 ;$ (g) $H_{s} / D=1$; and (h) $H_{s} / D=2$ 
Lateral boundary effects in centrifuge

foundation tests

Ullah, Hu, Stanier and White

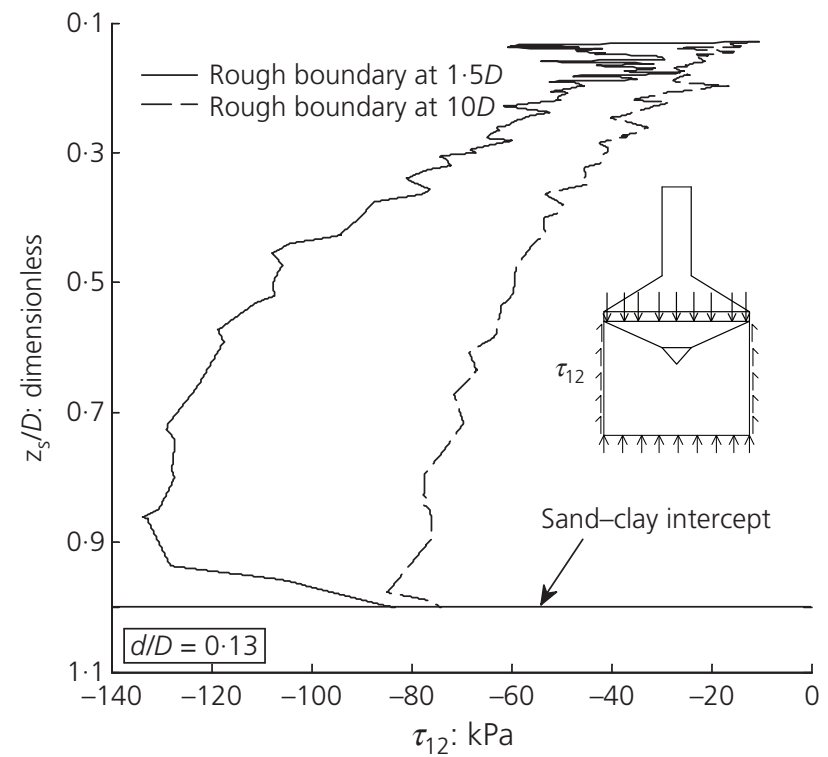

(a)

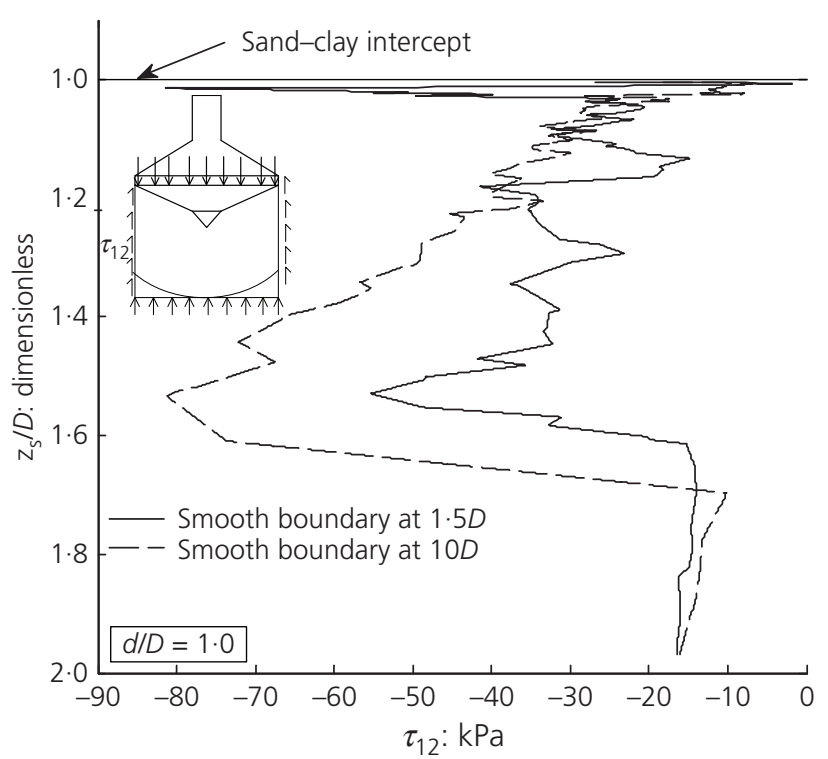

(b)

Figure 13. Mobilised shear stresses $\left(\tau_{12}\right)$ along the edge of the spudcan: (a) RB for $d / D=0.13, H_{s} / D=1.0$ and (b) $S B$ for $d / D=1.0$, $H_{s} / D=1 \cdot 0$

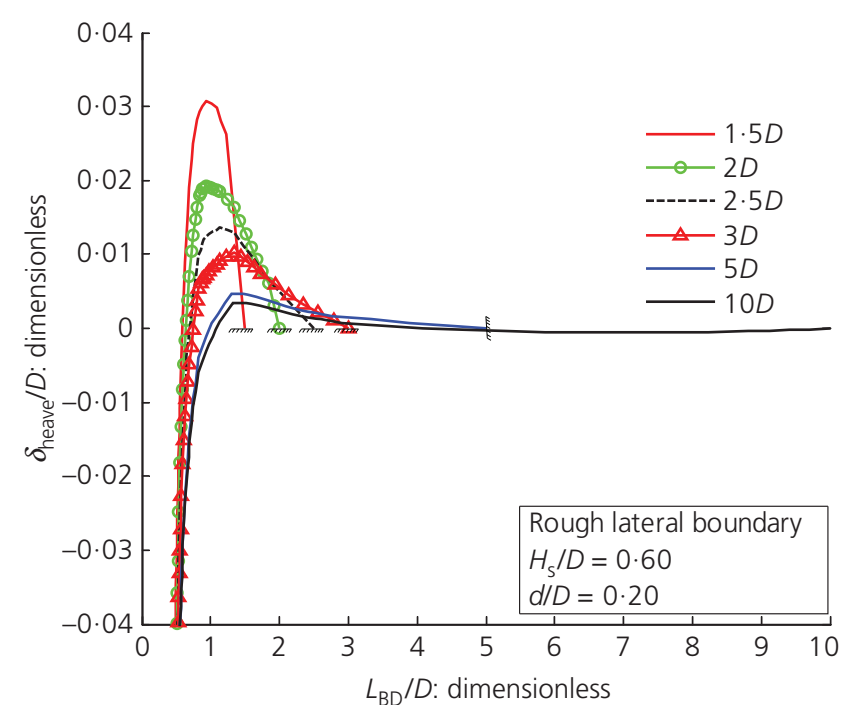

(a)

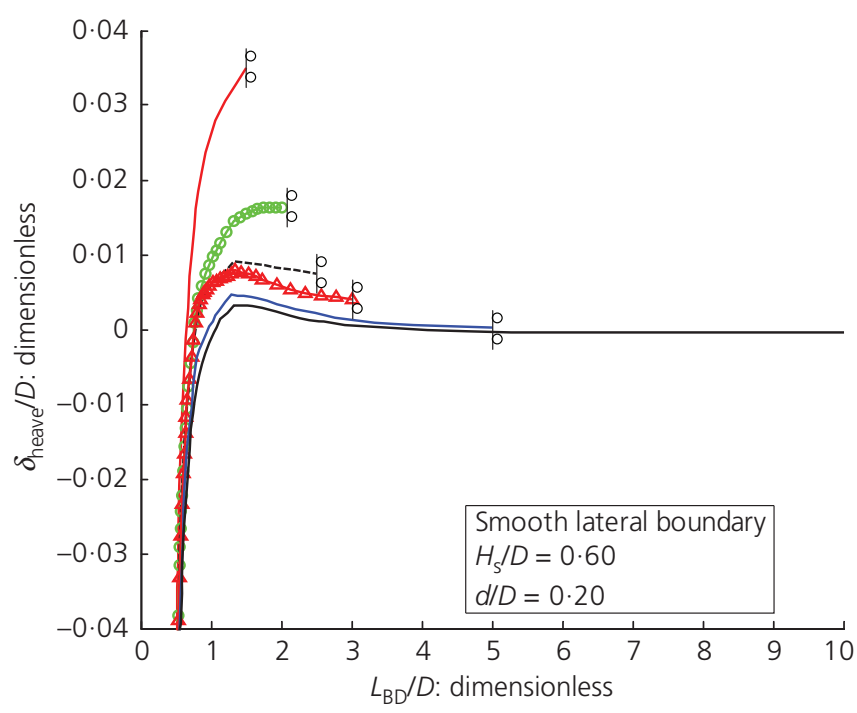

(b)

Figure 14. Surface heave profile at normalised depth $(d / D)$ of 0.20 for $H_{s} / D=0.60$ : (a) RB and (b) SB

the diagram can be used to check whether the strongbox dimensions are adequate for performing foundation penetration tests in the centrifuge that are not influenced by boundary effects.
In general, for $\mathrm{UC}$, minimum $L_{\mathrm{BD}} / D=1.5$ is recommended for an $\mathrm{RB}$, whereas $L_{\mathrm{BD}} / D=2$ is recommended for an $\mathrm{SB}$. Minimum $L_{\mathrm{BD}} / D=5$ is suggested for US irrespective of the boundary roughness. 


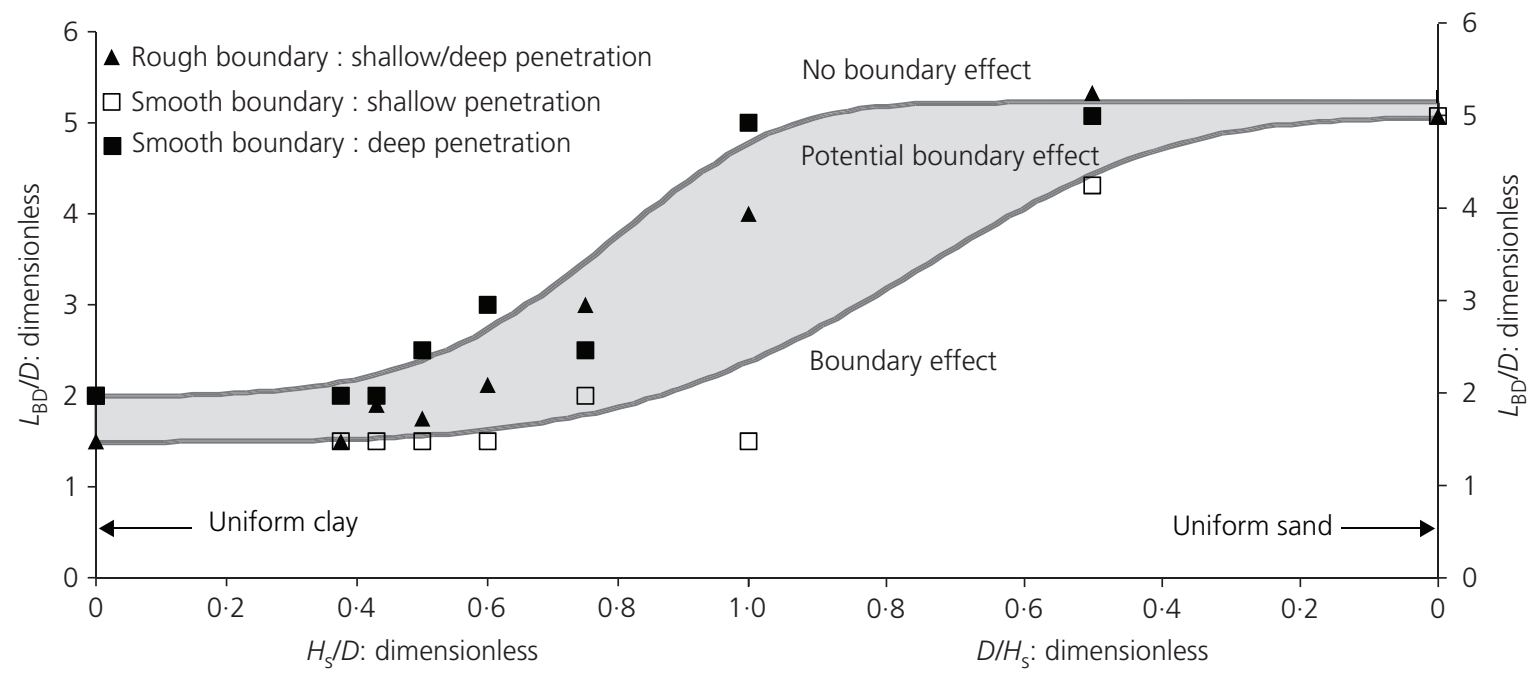

Figure 15. Centrifuge test design chart for estimating the safe normalised lateral boundary distance

For $\mathrm{SC}$, greater $H_{\mathrm{s}} / D$ ratios require larger strongboxes. For deep penetration tests, an RB is more suitable for a range of $0<H_{\mathrm{s}} / D \leq 2$ if sufficient box size is not available. If only shallow penetration is of interest, then an SB will allow the use of a smaller strongbox.
Although a typical spudcan foundation geometry was used in all the numerical analyses, the design chart presented can also be used for other circular or conical foundation where there is no significant difference in mechanisms. It is also expected that the boundary effects will be more significant for

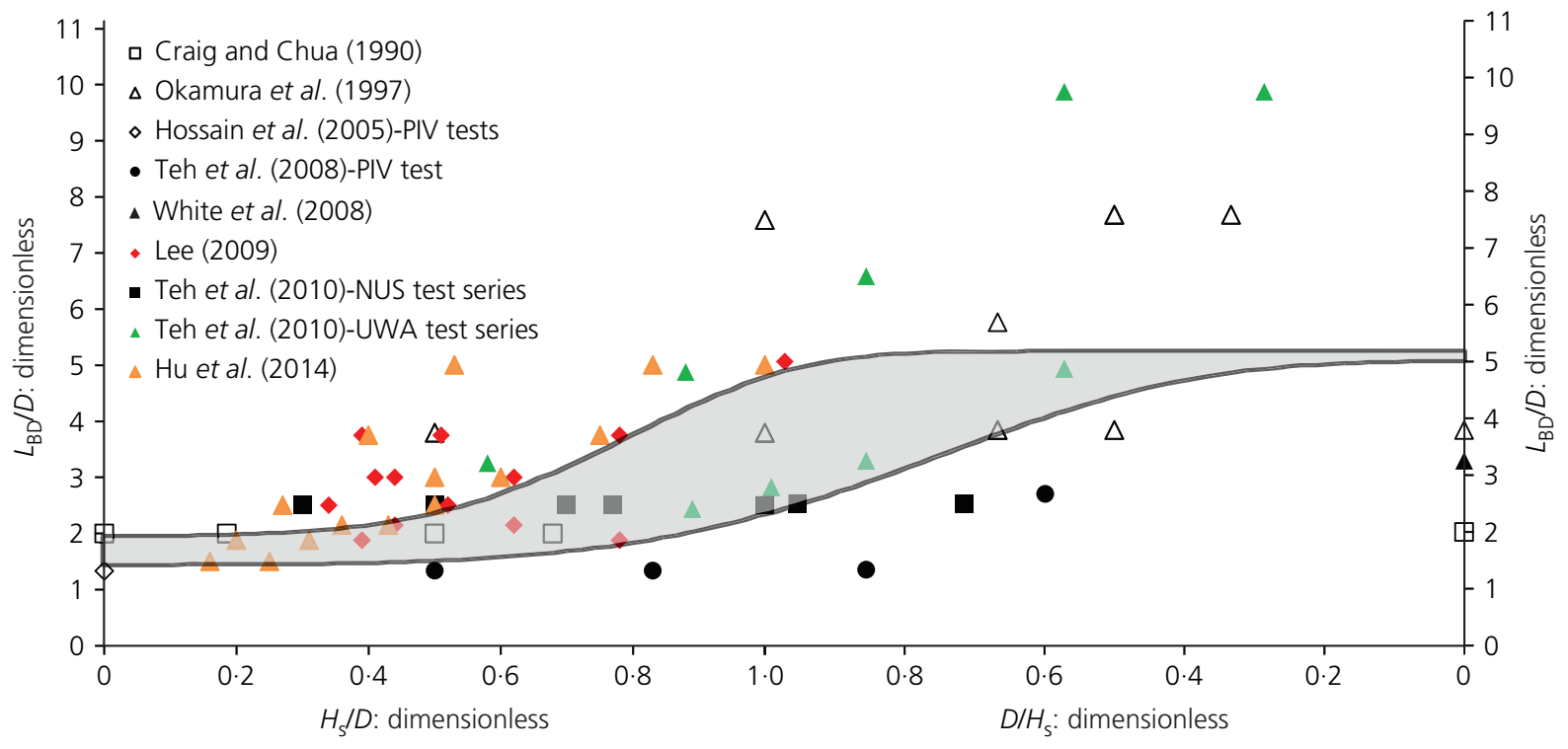

Figure 16. Reported normalised lateral boundary distance in previously published centrifuge tests against the proposed design chart. NUS, National University of Singapore; PIV, particle image velocimetry; UWA, University of Western Australia 
International Journal of Physical Modelling in Geotechnics Volume 17 Issue 3
Lateral boundary effects in centrifuge

foundation tests

Ullah, Hu, Stanier and White dense sand, thus requiring a larger strongbox for a given foundation size.

A wide range of published centrifuge modelling studies have been collated and the lateral boundary distances were compared against the proposed design chart (Figure 16). Many tests were performed with inadequate strongbox dimensions, especially for US where none of the tests reported satisfy the minimum strongbox criterion. On the other hand, there were plenty of tests performed falling in between the bounds of the proposed curves (implying the potential for boundary effects) and lying above it (implying no boundary effects). The actual impact of the strongbox boundary on these tests will also depend on the roughness condition of the boundary, which is not generally reported in the literature.

\section{Conclusions}

LDFE analyses were conducted to determine the container dimensions required in geotechnical centrifuge testing, to eliminate the boundary effects. Spudcan penetration in UC, US and loose sand overlying UC has been considered, as well as RB and SB conditions. The LDFE results were used to define adequate container dimensions leading to a design chart for the minimum container size under different soil layer profiles and spudcan sizes. The main conclusions are as follows.

- For centrifuge testing in UC, the lateral boundary measured from the centre of the foundation should be kept at a distance of at least $L_{\mathrm{BD}} / D=1.5$ for an $\mathrm{RB}$ and at $L_{\mathrm{BD}} / D=2$ for an $\mathrm{SB}$.

- For US, the required lateral boundary distance $\left(L_{\mathrm{BD}}\right)$ is greater than UC as the sand becomes stronger with depth and the full plastic flow-round mechanism is not formed. A minimum $L_{\mathrm{BD}} / D=5$ is recommended in this case.

- For the SC stratigraphy, the required boundary distance is dependent on the sand layer thickness over foundation diameter ratio $\left(H_{\mathrm{s}} / D\right)$. In general, greater $H_{\mathrm{s}} / D$ ratios require greater boundary distances $\left(L_{\mathrm{BD}} / D\right)$.

- For majority of the stratigraphies studied, the RB placed in proximity to the foundation edge significantly increased the penetration resistance and the SB decreased it, which illustrates the significant effect of the boundary roughness condition. The mobilised shear stresses along the plug periphery can increase or decrease depending on the lateral boundary distance. In addition, the soil surface heave profile depends on the lateral boundary distance.

- The results of LDFE analyses are summarised into a single design chart to guide strongbox and model dimensions prior to starting tests in the centrifuge involving large offshore foundations.

\section{ACKNOWLEDGEMENTS}

The work forms part of the activities of the Centre for Offshore Foundation Systems (COFS) at the University of Western Australia, which is supported by the Lloyd's Register Education Trust as a Centre of Excellence and is a node of the Australian Research Council (ARC) Centre of Excellence in Geotechnical Science and Engineering. The authors acknowledge the financial contribution of the ARC through Discovery Project No. 1096764. The authors also thank Dr Long Yu from Dalian University of Technology for help in modifying the current RITSS code. The first author acknowledges the various discussions he had with Dr Mi Zhou of COFS while writing this paper. The fourth author is supported by the Shell Energy and Minerals Institute (EMI) Chair in Offshore Engineering.

\section{REFERENCES}

Ahmadi MM and Robertson PK (2008) A numerical study of chamber size and boundary effects on CPT tip resistance in NC sand. Scientia Iranica 15(5): 541-553.

Bolton MD (1986) The strength and dilatancy of sands. Géotechnique 36(1): 65-78, http://dx.doi.org/10.1680/geot. 1986.36.1.65.

Bolton MD, Gui MW, Garnier J et al. (1999) Centrifuge cone penetration tests in sand. Géotechnique 49(4): 543-552, http://dx.doi.org/10.1680/geot.1999.49.4.543.

Carter JP and Balaam NP (2006) AFENA User Manual Version 6. Centre for Geotechnical Research, University of Sydney, Sydney, Australia.

Craig WH and Chua K (1990) Deep penetration of spudcan foundations on sand and clay. Géotechnique 40(4): 541-556, http://dx.doi.org/10.1680/geot.1990.40.4.541.

Das BM (2010) Geotechnical Engineering Handbook. J.Ross Publishing, Plantation, FL, USA.

Ghafghazi M (2011) Towards Comprehensive Interpretation of the State Parameter from Cone Penetration Testing in Cohesionless Soils. PhD thesis. Faculty of Graduate Studies (Civil Engineering)University of British Columbia, Vancouver, Canada.

Hansen JB (1970) A Revised and Extended Formula for Bearing Capacity. The Danish Geotechnical Institute, Copenhagen Denmark, vol. 28, pp. 5-11.

Hossain MS and Randolph MF (2009) New mechanism based design approach for spudcan foundations on single layer clay. Journal of Geotechnical and Geoenvironmental Engineering, ASCE 135(9): 1264-1274.

Hossain MS, Hu Y and Randolph MF (2004) Bearing behaviour of spudcan foundation on uniform clay during deep penetration. In Proceedings of the 23rd International Conference on Offshore Mechanics and Arctic Engineering, Vancouver, Canada (OMAET Committee (ed.)). ASME Press, New York, USA, vol. CD, pp. OMAE2004-5113. 
International Journal of Physical Modelling in Geotechnics Volume 17 Issue 3
Lateral boundary effects in centrifuge

foundation tests

Ullah, Hu, Stanier and White
Hossain MS, Hu Y, Randolph MF and White DJ (2005) Limiting cavity depth for spudcan foundations penetrating clay. Géotechnique 55(9): 679-690, http://dx.doi.org/10.1680/ geot.2005.55.9.679.

Houlsby GT and Martin CM (2003) Undrained bearing capacity factors for conical footings on clay. Géotechnique 53(5): 513-520, http://dx.doi.org/10.1680/geot.2003.53.5.513.

Hu Y and Randolph MF (1998a) H-adaptive FE analysis of elasto-plastic non-homogeneous soil with large deformation. Computers and Geotechnics 23(1/2): 61-83.

Hu Y and Randolph MF (1998b) A practical numerical approach for large deformation problems in soil. International Journal for Numerical and Analytical Methods in Geomechanics 22(5): 327-350.

Hu Y, Randolph M and Watson P (1999) Bearing response of skirted foundation on nonhomogeneous soil. Journal of Geotechnical and Geoenvironmental Engineering 125(11): 924-935.

Hu P, Stanier SA, Cassidy MJ and Wang D (2014) Predicting peak resistance of spudcan penetrating sand overlying clay. Journal of Geotechnical and Geoenvironmental Engineering 140(2): 04013009.

Last NC (1979) Cone penetration tests on samples of dry Hokksund sand in a rigid walled chamber. Norwegian Geotechnical Institute, Oslo, Norway, NGI Report No. 52108-8.

Lee KK (2009) Investigation of potential spudcan punch through failure on sand overlying clay soils. In School of Civil \& Resource Engineering. PhD thesis, University of Western Australia, Perth, Australia, pp. 1-218.

Lee KK, Randolph MF and Cassidy MJ (2013) Bearing capacity on sand overlying clay soils: a simplified conceptual model. Géotechnique 63(15): 1285-1297, http://dx.doi.org/10.1680/ geot.12.P.176.

Martin C and Randolph M (2001) Applications of the lower and upper bound theorems of plasticity to collapse of circular foundations. In Proceedings of the 10th International Conference on Computer Methods and Advances in Geomechanics, Tucson, Arizona (Desai CS, Harpalani S, Kemeny J and Kundu T (eds)). CRC press, Tucson, AZ, USA, vol. 2, pp. 1417-1428.

Okamura M, Takemura J and Kimura T (1997) Centrifuge model tests on bearing capacity and deformation of sand layer overlying clay. Soils and Foundations 37(1): $73-88$.

Parkin AK and Lunne T (1982) Boundary effects in laboratory calibration of a cone penetrometer for sand. In Proceedings of the Second European Symposium on Penetration Testing, Amsterdam, the Netherlands (Verruijt A (ed.)). CRC press, Amsterdam, the Netherland, pp. 761-767.

Phillips R and Valsangkar AJ (1987) An Experimental Investigation of Factors Affecting Penetration Resistance in Granular Soils in Centrifuge Modelling. Cambridge
University Engineering Department (CUED), Cambridge, UK, Technical report, TR No. 210.

Qiu G and Henke S (2011) Controlled installation of spudcan foundations on loose sand overlying weak clay. Marine Structures 24(4): 528-550.

Schnaid F and Houlsby GT (1991) An assessment of chamber size effects in the calibration of in situ tests in sand. Géotechnique 41(3): 437-445, http://dx.doi.org/10.1680/geot.1991.41.3.437.

Stewart DP (1992) Lateral Loading of Piled Bridge Abutments Due to Embankment Construction. PhD thesis, University of Western Australia, Perth, Australia.

Teh KL (2007) Punch Through of Spudcan Foundation on Sand Overlying Clay. $\mathrm{PhD}$ thesis, National University of Singapore, Singapore.

Teh KL, Cassidy MJ, Leung CF et al. (2008) Revealing the bearing capacity mechanisms of a penetrating spudcan through sand overlying clay. Géotechnique 58(10): 793-804, http://dx.doi.org/10.1680/geot.2008.58.10.793.

Teh KL, Leung CF, Chow YK and Cassidy MJ (2010) Centrifuge model study of spudcan penetration in sand overlying clay. Géotechnique 60(11): 825-842, http://dx.doi.org/10.1680/ geot.8.P.077.

Wang CX and Carter JP (2002) Deep penetration of strip and circular footings into layered clays. The International Journal of Geomechanics 2(2): 205-232.

White DJ, Teh KL, Chow YK and Leung CF (2008) A comparison of the bearing capacity of flat and conical circular foundations on sand. Géotechnique 58(10): 781-792, http:// dx.doi.org/10.1680/geot.2008.3781.

Yu L, Hu Y, Liu J, Randolph MF and Kong X (2012) Numerical study of spudcan penetration in loose sand overlying clay. Computers and Geotechnics 46: 1-12.

Zhou H (2008) Numerical study of geotechnical penetration problems for offshore applications. In School of Civil and Resource Engineering. PhD thesis, University of Western Australia, Perth, Australia, pp. 1-234.

\section{HOW CAN YOU CONTRIBUTE?}

To discuss this paper, please email up to 500 words to the editor at journals@ice.org.uk. Your contribution will be forwarded to the author(s) for a reply and, if considered appropriate by the editorial board, it will be published as discussion in a future issue of the journal.

International Journal of Physical Modelling in Geotechnics relies entirely on contributions from the civil engineering profession (and allied disciplines). Information about how to submit your paper online is available at www.icevirtual library.com/page/authors, where you will also find detailed author guidelines. 